\title{
Producciones constructivas y decorativas. Indicadores cronológico-culturales de la alta Edad Media hispánica
}

\section{Constructive productions and decorative Productions. Chrono-cultural indicators for the hispanic Early Middle Ages}

\author{
Luis Caballero Zoreda \\ Instituto de Historia. CCHS. CSIC
}

\begin{abstract}
RESUMEN
Se analiza la producción arquitectónica de cinco edificios singulares de nuestra alta Edad Media a través de sus características, las relaciones entre los talleres de albañilería y de sillería (sillería de regla y de escuadra, apertura de canteras o sillería reutilizada) y los de escultura (ex novo o reutilizada; talleres externos u ocasionales, a pie de obra o sobre el edificio). Estas relaciones productivas varían desde unos casos donde aparentemente son ajenas, de manera que la construcción acomoda una decoración realizada sin tener presente el edificio, a otros en que ambas producciones están cada vez más integradas. Dos conjuntos decorativos ofrecen datos singulares en estas relaciones, procediendo como elementos novedosos que se pueden suponer indicadores de importantes diferencias culturales y cronológicas propias de la alta Edad Media. Uno es el del mobiliario de culto (canceles y altares). Y otro el de impostas y frisos arquitectónicos que, vinculados o no a los edificios conservados y presentes en los talleres de Mérida y Toledo, se suponen característicos de la arquitectura posterior al año $711{ }^{1}$.
\end{abstract}

\section{SUMMARY}

The architectonic production of five remarkable buildings from our early Middle Ages is analysed through their characteristics, the relationships between bricklaying and mason workshops (straight and square masonty work, quarry opening or reused masonry), and carving workshop (ex novo or reused; external or temporary workshops; close to or on the building workshops). These production relationships vary from cases that are apparently unconnected, in which the construction holds ornaments that were not made keeping the building in mind, to others in which both productions are increasingly integrated. Two decorative sets provide remarkable data on these relationships, becoming original elements that can be

${ }^{1}$ Proyecto de investigación "Análisis Arqueológico de la Arquitectura Alto Medieval en Asturias (II)", HAR201127579, Ministerio de Educación y Cultura. El texto no sería el mismo sin las atinadas observaciones y preguntas de María de los Ángeles Utrero, a quien se las agradezco. También agradezco la lectura y observaciones efectuadas por Isaac Sastre de Diego y Francisco Moreno Martín. A todos ellos debo el conocimiento de sus textos inéditos. indicative of main cultural and chronological differences, representative of the early Middle Ages. The first one corresponds to the worship furniture (partitions and altars). The second one is the architectural imposts and friezes, which are supposedly characteristic of the architecture after the year 711, linked or not with preserved buildings and those present in the workshops of Mérida and Toledo.

PALABRAS CLAVES: Arqueología de la Arquitectura, producción arquitectónica, arquitectura abovedada, talleres constructivos y decorativos, reutilización, aparejos, molduras, impostas, frisos, instalaciones litúrgicas, Santa María de Melque (Toledo), Santa Lucía de El Trampal (Cáceres), San Juan de Baños (Palencia), San Pedro de La Nave (Zamora), Quintanilla de Las Viñas (Burgos), Mérida, Córdoba, Toledo, Guarrazar, Sonseca-Orgaz.

KEY WORDS: Architectural archaeology, architectonic production, vaulted architecture, decorative and constructive workshop, reuse, bonding, moulding, imports, friezes, liturgical installations, Santa María de Melque (Toledo), Santa Lucía de El Trampal (Cáceres), San Juan de Baños (Palencia), San Pedro de La Nave (Zamora), Quintanilla de Las Viñas (Burgos), Mérida, Córdoba, Toledo, Guarrazar, Sonseca-Orgaz.

Esta propuesta se basa en los resultados conseguidos por análisis de Arqueología de la Arquitectura en edificios hispanos de época altomedieval. Utilicé este método como un sistema eficaz para contrastar y desarrollar el paradigma "rupturista y mozarabista" que propuse en 1994 sobre estas arquitecturas (entendiendo "mozárabe" como "de influjo islámico", dentro de la tradición historiográfica española). Este nuevo paradigma propone superar el "continuista y visigotista", entonces consensuado, que supone que la arquitectura hispánica tardoantigua evolucionaría, 
gracias a una influencia bizantina, para dar lugar en el siglo VII a la visigoda caracterizada por edificios de plantas compartimentadas, con aparejo de sillería, abovedados y decorados con escultura y que, pese a la invasión islámica, seguiría transmitiendo sus características a la de siglos posteriores. Según mi alternativa, la arquitectura de estas características debe considerarse altomedieval, producida por la llegada de talleres expertos con posterioridad a los sucesos del año 711, cuando se abrió un "canal de transmisión de lo clásico" gracias a la implantación del estado omeya en nuestra Península. La potencialidad del método supera su mero carácter auxiliar de la demostración y permite plantear una Historia de la Arquitectura basada en la producción arquitectónica, distinta a la tradicional centrada en la evolución estilística y de corte continuista (Schlunk y Hauschild 1978; Palol i Salellas 1991; Caballero 1994/95; Bango 2001; Caballero y Utrero 2005; Utrero 2010. Caballero 2012; Caballero y Moreno e.p.; Caballero y Utrero 2012; Utrero e.p. Estado de la cuestión, descripción de edificios, análisis y crítica, Utrero 2006, "Capítulo VII", especialmente 226 y 234-236, "Parte III. Conclusiones", 203, y "Parte IV. Catálogo”. S.a. 2010).

\section{SANTA LUCÍA DE EL TRAMPAL (CÁCERES) Y SANTA MARÍA DE MELQUE (TOLEDO)}

Las iglesias de El Trampal y Melque, situadas en el centro de la Península, formaban parte de monasterios donde se introdujeron por primera vez soluciones técnicas propias del oriente del Mediterráneo. Son edificios abovedados y decorados de acuerdo a su arquitectura y su diferente organización. Sus instalaciones litúrgicas no se adecuan a la arquitectura y mantienen formas tradicionales, aunque con modelos decorativos novedosos. Dato la construcción de ambos conjuntos en la segunda mitad del siglo VIII, principalmente por las cerámicas aparecidas en sus niveles de fundación (El Trampal: Caballero y Sáez 1999. Melque: Caballero y Latorre 1980; hoy refuto su datación visigoda: Caballero y Fernández Mier 1999; Caballero 2007; Caballero y Moreno 2013).

\section{Producción constructiva en El Trampal y Melque}

Los sillares y sillarejos necesarios para construir El Trampal (Figs. 1 y 3.1), así como los ladrillos empleados en sus muros y las tejas planas necesarias para los tejados proceden de expolio o acarreo. Solamente la mampostería, de pequeño formato, se recogió de la superficie, en cercanos afloramientos de pizarra. Un ejemplo de punto de aprovisionamiento, entre otros que pudieron surtirle, es el yacimiento romano de Las Torrecillas (situado a algo más de $10 \mathrm{~km}$ en línea recta a su norte) de donde procede una estela funeraria similar a las reutilizadas en la iglesia como umbrales de los canceles (Caballero y Sáez 1999: 19-20 y 84-85).

La edificación se realiza por albañiles y canteros que trabajan en estrecha colaboración. Los muros son de mampostería reforzada puntualmente con verdugos de ladrillo, sillarejos en hiladas intermedias y encadenados en las esquinas. En la cabecera ocurre lo mismo aunque se invierte la proporción, predominando la sillería. Llama la atención que en las bóvedas se sustituya un número significativo de dovelas de piedra por ladrillos, en una labor propia de albañiles que, a la vez, indica la escasez de sillares. Los canteros, que desconocían el uso de la escuadra, retallaban lo mínimo imprescindible los sillares. Por ejemplo, para conseguir las dovelas procuraban efectuar un único corte oblicuo a los sillares. Pero ello no impidió que tallaran los marcos de puertas y ventanas, las piezas de los pilares y las dovelas de arcos y bóvedas, en ocasiones de compleja estereotomía. Algunos canteros más especializados dirigían el trabajo y cortaban las piezas, mientras que los albañiles realizaban la mampostería y auxiliaban en las labores de cantería, ayudando a colocar los sillares preparados por los canteros a pie de obra. El taller de carpintería realizó los imprescindibles andamios y cimbras, la demás carpintería de obra y debió construir una pérgola o galería (en el ala norte del monasterio) con solana armada en la fábrica de mampostería. Los albañiles vertieron los suelos de hormigón hidráulico y finalmente enfoscaron el edificio, primero con una capa de mortero que no cubría toda la superficie de mampuestos y sillares y en la que se hicieron incisiones horizontales para sujetar la segunda capa de enlucido. Sobre la primera capa aún fresca se efectuó un grafito, aprovechando como líneas de traza las incisiones de obra, datado en el siglo VIII (dovelas de ladrillos y sillería tallada: Caballero y Sáez 1999: planos 21-22 y fig. 48; grafito: Caballero y Velázquez 1999).

En Melque, las cuadrillas de canteros y albañiles estaban más diferenciadas y especializadas (Figs. 2 y 3.2). Los canteros dirigen la obra de la iglesia mientras que los albañiles ordenan la de los edificios monásticos, ambas sincrónicas, colaborando ambos equipos en las obras que no son de su competencia.

Cada taller y cada obra utiliza su propio material, ambos granitos locales; el de la iglesia, inalterado o "fresco", obtenido en cantera; y el del monasterio, 

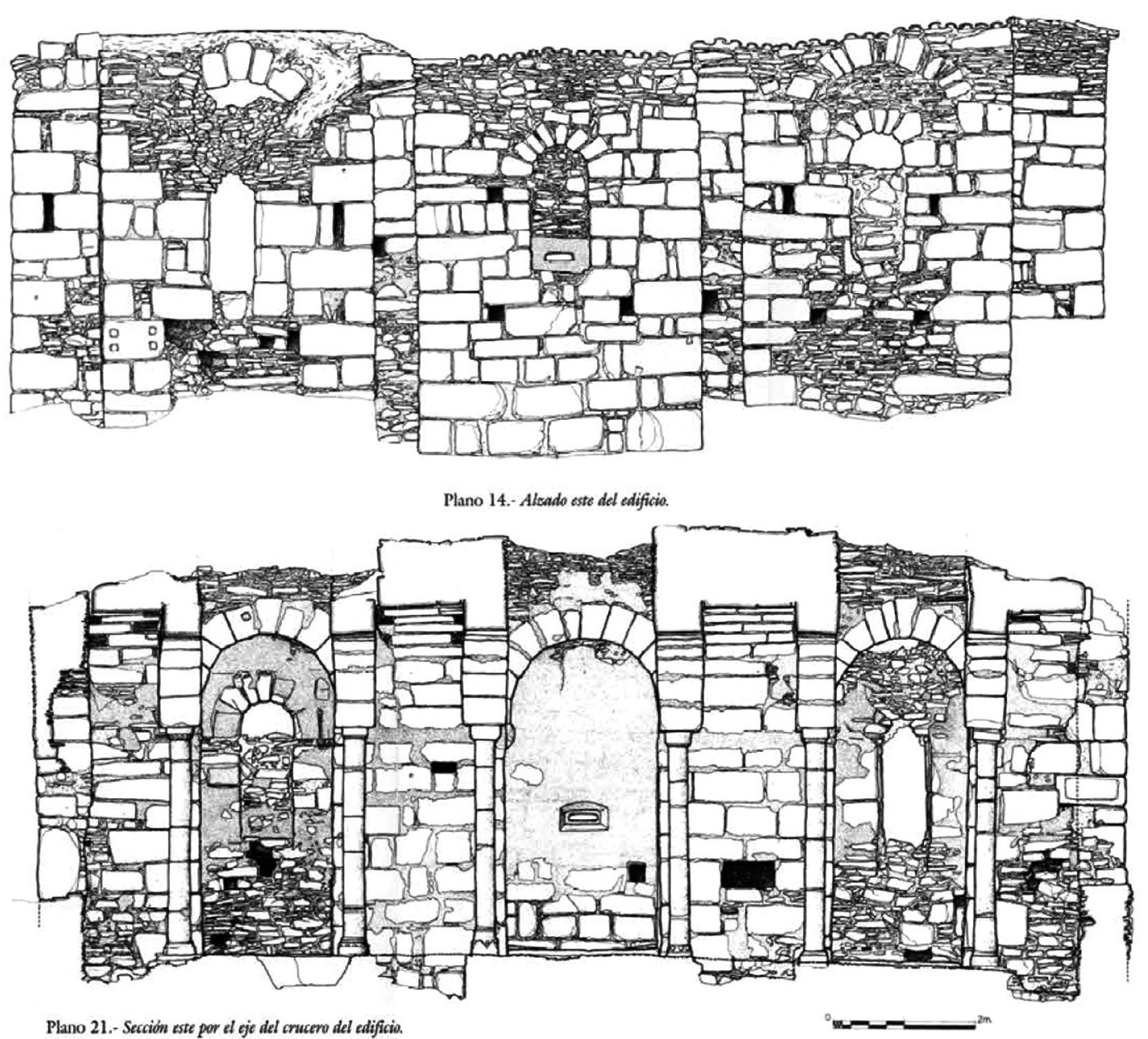

Plano 21.- Sección este por el gje del crucero del edifficio

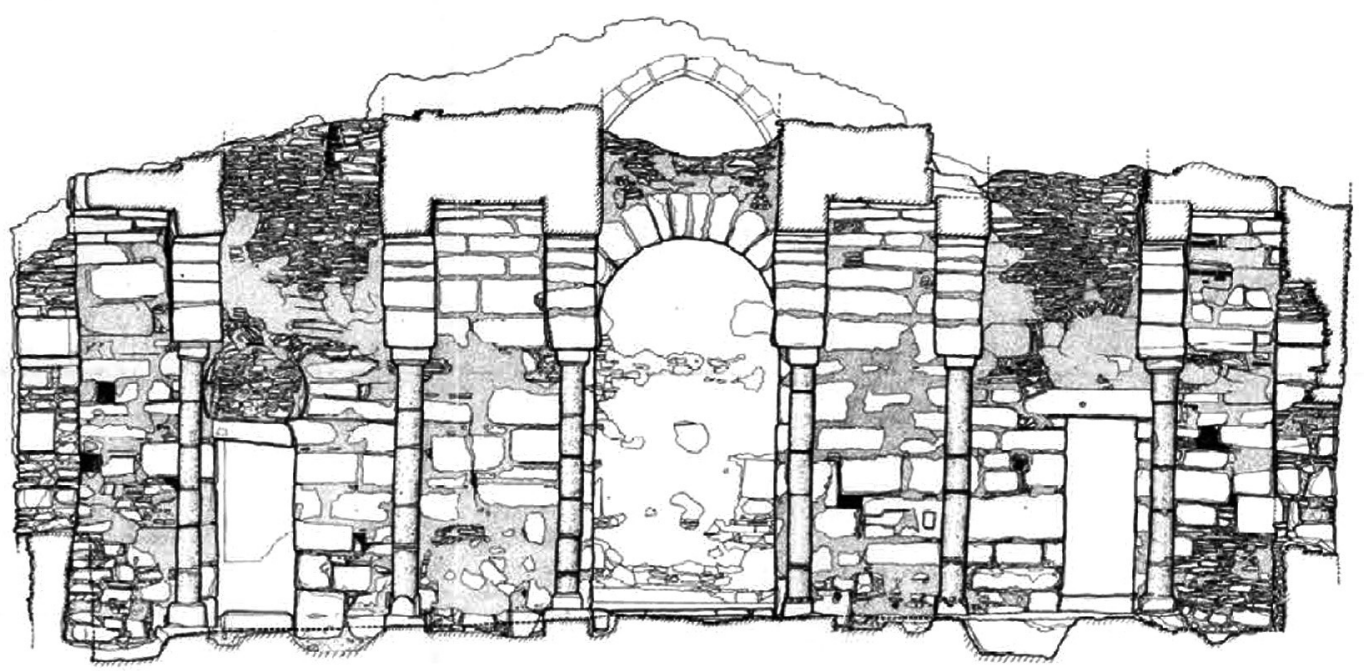

Plano 22.- Sección oeste por el eje del crucero del adificio.

Figura. 1. Santa Lucía de El Trampal (Cáceres). Alzado Este y secciones por el "transepto" hacia este y oeste. Caballero y Sáez Lara 1999. Escala 1/115. 

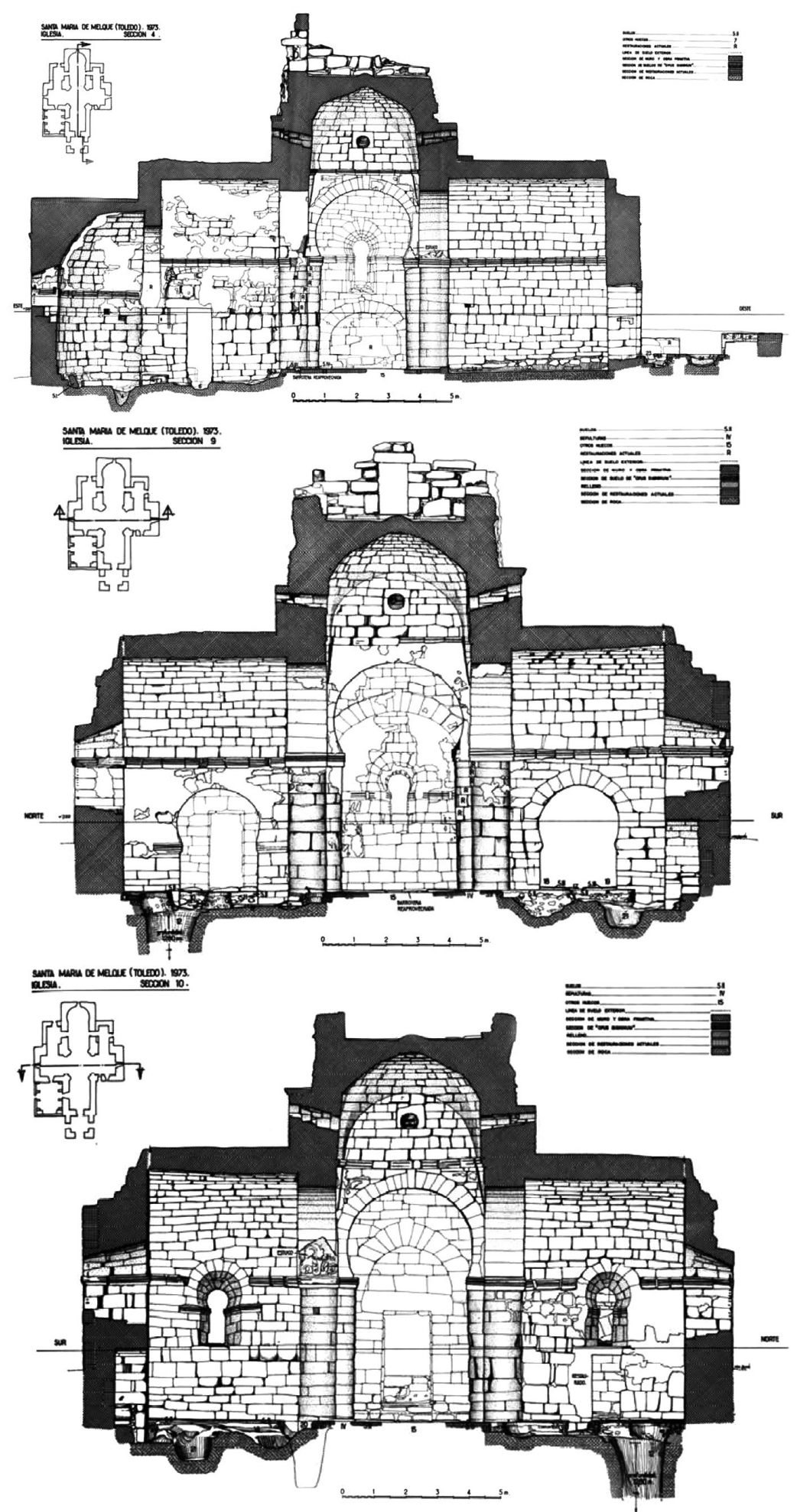

Figura. 2. Iglesia de Santa María de Melque (Toledo). Sección longitudinal a sur y transversales a este y oeste. Caballero y Latorre 1980. Escala 1/200. 
"rubefactado", alterado en suelos de arcilla, procedente del aprovechamiento de bolos superficiales ${ }^{2}$. En el segundo caso es posible que fueran los propios albañiles los que obtuvieran los mampuestos, de tamaño grande, eligiendo y cortando los bolos, o que esta labor la realizara una cuadrilla especializada de picapedreros.

En el monasterio, los albañiles cuentan con una cuadrilla de canteros para reforzar las esquinas con cadenas y para tallar y colocar las piezas de forma, los marcos de vanos adintelados y arcuados y las pilastras; y en la iglesia, los albañiles colaboran ayudando a elevar los muros y rellenando sus núcleos. Los canteros no utilizan la escuadra sino solo la regla para tallar los sillares, de modo que una vez ajustados, presentan características específicas como codos, desdobles de hiladas e hiladas onduladas. También es característica cierta alternancia de sillares a soga y a tizón. Los albañiles aparejan grandes mampuestos de modo homogéneo, con abundante cal (Fig. 3.2). Tanto en el interior de la iglesia como en el monasterio, el mortero de las juntas de mampuestos y sillares formaba listeles en relieve. En la iglesia los suelos fueron de losas, mientras que en los edificios y en los patios monásticos solo tenemos información de suelos de albero, tierra limpia apisonada y mezclada con algo de cal. La calidad alcanzada por el taller de albañilería de Melque no se refiere a una tradición local, no solo por el aparejo de su mampostería sino también por el empleo de la cal que en el último tramo de la época visigoda parece perdido. En las fases II y III de Vega Baja (Toledo), posteriores al siglo VI, los edificios son de mampostería "trabados con tierra y cuerpos de tapial" aunque "con revocos de cal de buena calidad" y de "cimientos de mampostería trabados con barro" y suelos de "arcilla compactada" (juntas: Caballero y Latorre 1980: 159; mortero de cal: Rojas y Gómez 2009: 84-85).

La capacidad del monasterio de Melque permitió que mientras pervivió, se mantuvieran sus talleres, con las lógicas transformaciones. El taller de sillería, aunque su aparejo perdió calidad, reformó la iglesia y la amplió adosando en un segundo momento la habitación trasera y probablemente las delanteras. También nuevos talleres de albañiles sustituyeron el suelo originario de losas por otro de hormigón hidráulico, más tarde restaurado, realizaron las murallas defensivas e introdujeron el aparejo de ladrillo. El "grupo productivo" regional al que pertenece el monasterio pudo servir para desarrollar otros trabajos. Su influencia está aún por estudiar comparándolo tipológicamente con otros aparejos emirales como los de Vascos y Talavera de la Reina. También se pudieron relacionar con los edificios de La Mata y Los Hitos, aunque se deben analizar con

\footnotetext{
${ }^{2}$ Agradezco la información geológica a Jesús Caballero García.
}

cuidado ambos edificios y su posible función y cronología antes de confirmarlo. La Mata tiene un sistema decorativo distinto al de Melque y existen dudas sobre su sistema constructivo que dificultan asimilarlo al de Melque; y la decoración de Los Hitos, distinta también a la de Melque, parece reutilizada en un edificio del que desconocemos con seguridad a qué tipo arquitectónico pertenece (Caballero y Latorre 1980: 289-292 y 298302, actualizado en Caballero 2007: 99-102; Caballero y Utrero 2005: fig. 4; Caballero y Moreno 2013; Los Vascos: Juan Ares 2000: 309-310 y 312; Talavera, aparejo de las torres 5-9 y material reutilizado: Martínez Lillo 1998: figs. 6 y 13).

Tuviera consecuentes o no los tuviera y al margen de su material, granito procedente de cantera, el taller de cantería de Melque ofrece semejanzas con otros edificios que considero construidos un siglo después o más tarde, como Baños, La Nave o Valdediós. Estas semejanzas se explican a causa de la común técnica del uso de la regla y el desconocimiento de la escuadra en la talla de la sillería; esto es, como una característica del nuevo ambiente técnico en que se encuadran estas

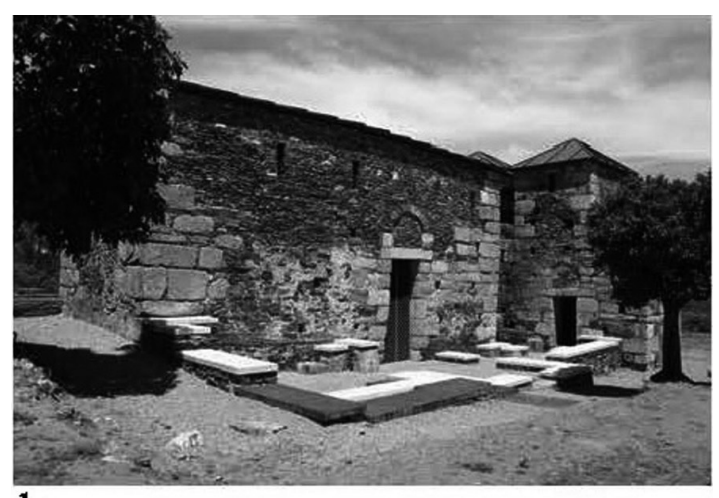

1

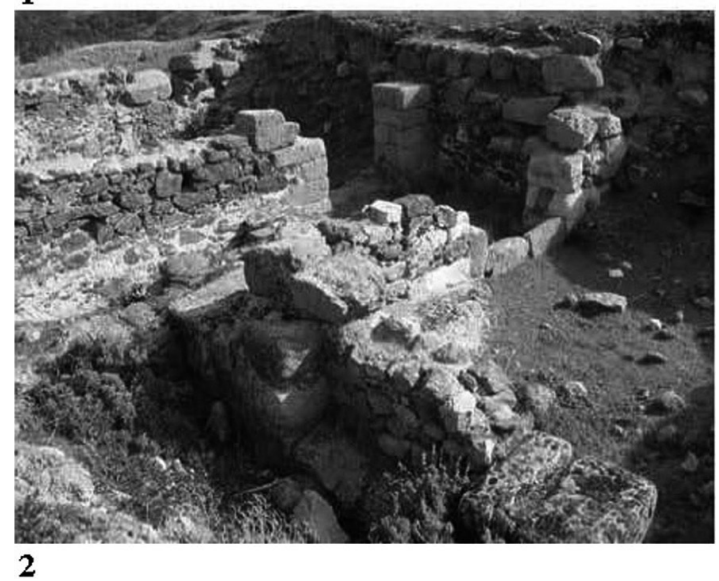

Figura. 3. 1. Muro sur del aula de El Trampal (restaurada la parte superior de los muros). 2. Muros del monasterio de Melque. 
iglesias, y del que el taller de cantería de Melque fue un introductor, y no como una dependencia directa de talleres. La técnica de regla tuvo que ser introducida en la Península por talleres alternativos, con sus variantes específicas; en distintos momentos, dentro de un periodo coetáneo post-visigodo; y con distinto éxito para cada taller (ambiente técnico: Bianchi 1996: 53. Caballero y Utrero 2005: fig. 4).

PRODUCCIÓN CONSTRUCTIVA Y DECORATIVA EN EL TRAMPAL y Melque

Sendos talleres de marmolistas, muy similares en su aprovisionamiento de expolio, repertorio y funcionamiento, trabajaron para ambas iglesias. Ambos sirvieron el mobiliario de altares y canceles, pero solo el de El Trampal decoró su arquitectura, mientras que un taller distinto de estuco decoró la de Melque.

La construcción de la iglesia de Melque estaba preparada para la decoración de estuco que se agarraba en las hendiduras de las molduras de imposta de las bóvedas, talladas en sillares de granito por los canteros (Fig. 4). La decoración cubría intradoses y arquivoltas de los arcos del crucero (con roleos surgiendo de cornucopias o vasos y friso de trifolios encadenados formando lúnulas, en ambos casos con rosetas); otros elementos donde quedan algunos restos, como pechinas y tímpanos del crucero; y probablemente las bóvedas de ábside, "anteábside" y crucero, donde no hay indicios. Los estucadores trabajaban, más que a pie de obra, sobre la obra misma una vez terminada y en estrecha relación con ella, pues marco arquitectónico y formas y temas decorativos se tenían que acomodar mutuamente. Una moldura similar a la imposta de Melque es la del porche del baño de Khirbat al Mafjar (Palestina), formada por perfiles que no sobresalen del plano de salida vertical, quizás porque tuviera la misma finalidad de agarre del estuco, aunque Hamilton supone que estuvo vista y no recubierta de estuco (Hamilton 1959: figs. 78-79, láms. XVII y CVII-CVIII).

Dada la estrecha relación entre arquitectura y decoración, supongo que el equipo de canteros y estucadores que realizó la iglesia de Melque llegó conformado y que debieron tener una misma procedencia, extranjera y oriental ${ }^{3}$. También es indicio de ello la forma y estructura del edificio; sus soluciones constructivas propias, como esquinas redondeadas,

\footnotetext{
${ }^{3}$ Según Larrea y Pastor 2012: 326, el pago de la ŷizya por los dimmís a través de prestaciones personales "pudo favorecer la transferencia de ideas y modelos constructivos y decorativos de raíz oriental".
}

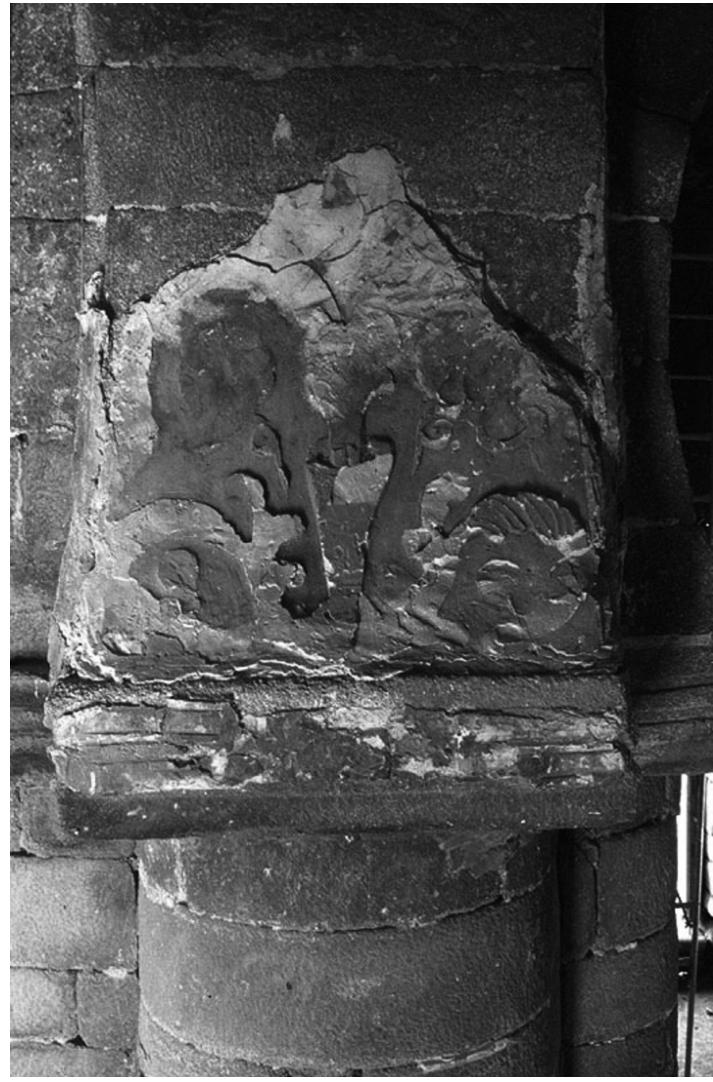

Figura. 4. Melque. Estuco del intradós del arco toral meridional del crucero de la iglesia.

arcos de herradura, arcos y platabandas de descarga, pechinas con aristas y bóvedas peraltadas y baída; y las decorativas, como las molduras de imposta y la técnica y los motivos decorativos de los estucos (Caballero y Latorre 1980: 719-726, lám. 40, entonces considerados del siglo VII; Garen 1992: 296-301; Caballero 1994-95: 340; Caballero y Utrero 2012).

En la arquitectura de la iglesia de Melque, el taller de marmolista solo debió intervenir para abastecer las columnas del arco del ábside, hoy perdidas, que procederían de expolio. Sirvió además el mobiliario litúrgico completo, el único altar y dos canceles. En cambio, en la iglesia de El Trampal, además de servir, como en Melque, la instalación litúrgica formada por los altares y canceles, el mismo taller preparó las piezas que se incorporaron a la arquitectura, columnas y sus cimacios e impostas de bóvedas (Melque: Caballero y Latorre 1980: figs. 2 y 82-83, ara de altar, y figs. 1, 4, 62, 83-85, 97 y 121-122, canceles; Caballero 2007: figs. 16 a 18, dos placas de cancel y un ara de altar. El Trampal, decoración arquitectónica y mobiliaria, Caballero y Sáez 1999: 122-130). 


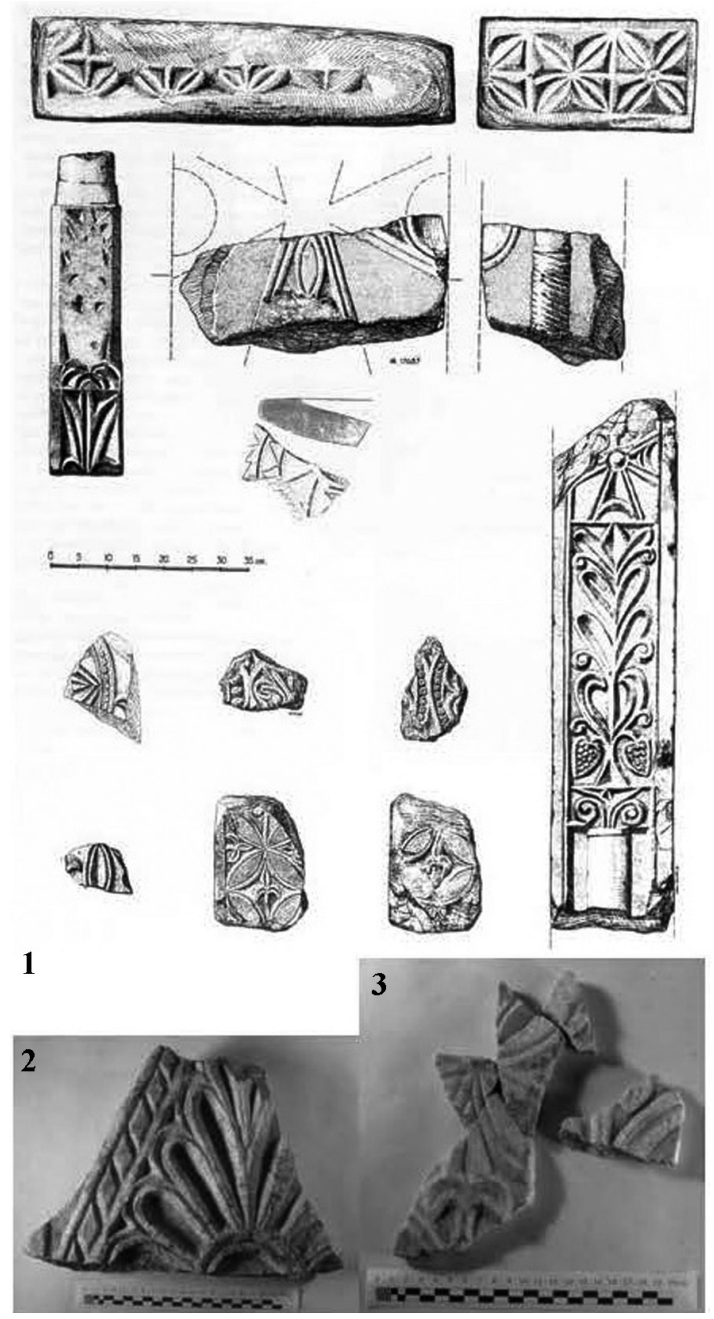

Figura. 5. Decoración de Melque. 1. Imposta y pilastrilla aparecidas en el monasterio, ara de altar, tondo del monasterio, placas y larguero de canceles. Caballero y Latorre 1980. 2 y 3. Placas de cancel aparecidas en excavación.

Otras decoraciones completan el conocimiento del sistema productivo de Melque. Algunos espacios de su monasterio se decoraron con piezas de mármol que procedían del mismo taller de marmolista que trabajó para la iglesia, como demuestran una pilastrilla y un tondo (¿con monograma?). Si la pilastrilla está a medio tallar, significaría que el taller realizó su trabajo a pie de obra. Un fragmento de una segunda ara decorada indica la existencia de otro centro eucarístico en el monasterio. Además, existió otro grupo decorativo, tallado por los canteros in situ, lo que atestigua de nuevo la independencia de cada parte de la obra. Así se decoraron las impostas del arco exterior del porche que daba paso al que suponemos palacio del abad, con un tema de círculos secantes y cruces que se repite
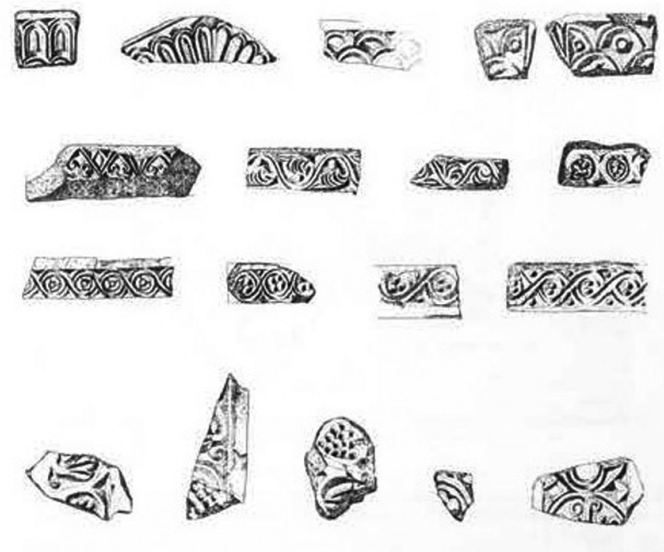

1
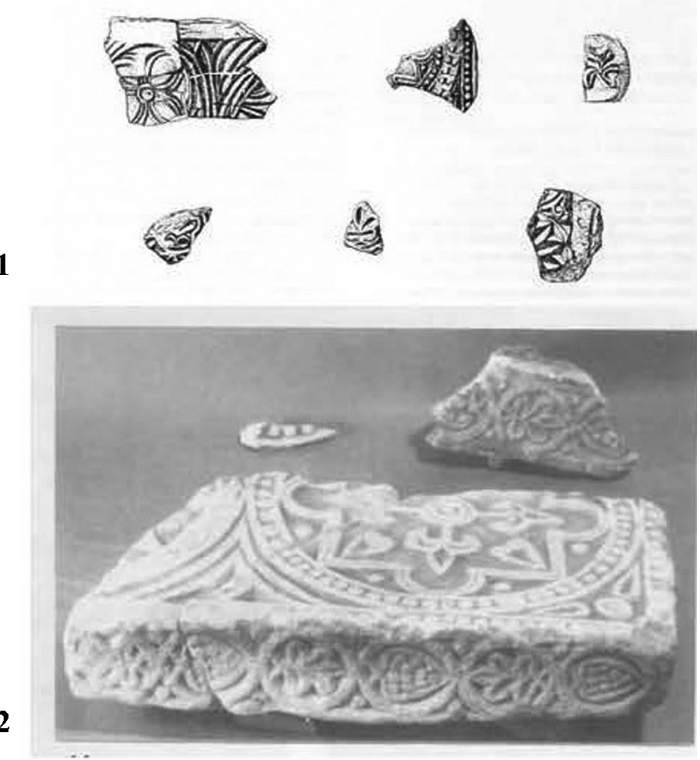

Figura. 6. 1. Escultura decorativa de El Trampal, cimacios e impostas largueros. 2. Placas de canceles. Caballero y Sáez Lara 1999.

en Córdoba y Toledo. Su material, granito en vez de mármol, la distinta pericia en su talla y el empleo de un sencillo tema decorativo, desconocido en el taller de marmolistas, indican su carácter excepcional, su pertenencia a una labor ajena a la marmolería que sirvió a la iglesia y el que ciertos canteros conocían las técnicas de escultura y repertorios locales (Fig. 5, 1. Caballero y Latorre 1980: figs. 26, 58 y 74. Segunda ara; Caballero 2007: fig. 19; Sastre de Diego 2009: 188).

Tanto en Melque como en El Trampal, las piezas de mármol se encargaron a las marmolerías que no trabajaban a pie de obra y cuyos artesanos no tenían una relación directa ni con la programación ni con la realización de la obra arquitectónica. Se solicitaban 
piezas "prefabricadas" al taller foráneo, acordando sus condiciones (elección de modelos, número de unidades y dimensiones); se servían; y se acoplaban donde era necesario por los canteros de la construcción. Al ser piezas de encargo, el arquitecto reserva el lugar en los muros y el suelo donde tenía que encajarse cada pieza según lo necesitara la obra. Consecuentemente, se ajustan en obra, recortando entonces los huecos de sujeción de acuerdo con la forma y tamaño de las piezas aportadas, como los canceles en El Trampal y Melque, o acomodándolas a los huecos preestablecidos, como las impostas y cimacios en El Trampal, cuidando solo la apariencia general. En la colocación de los canceles de Melque intervinieron los carpinteros para armar marcos de trabe y pies derechos que se sujetaban a la construcción y al que se acomodaban las placas de mármol. En la colocación de las impostas y cimacios de El Trampal (Fig. 7,1-3), no importaba la continuidad de los motivos de las piezas, ni que los extremos decorados de cimacios o impostas quedaran ocultos en el muro, o que las impostas correspondientes a arcos vecinos, de ejes perpendiculares entre sí, se superpusieran perdiendo un común plano horizontal para sus "líneas de imposta" (Melque: Caballero y Latorre 1980: 292-293 y 596; Caballero 2007: 99 y 101; El Trampal: Caballero y Sáez 1999: 96-97 y 162-163).

Las producciones litúrgicas en mármol de ambas iglesias pertenecen a un mismo horizonte productivo dada su homogeneidad de material reutilizado, técnica, forma y estilo, aunque no se puede asegurar que fueran realizadas por un mismo taller. Cada una se debe vincular a su centro urbano, Mérida y Toledo. La distribución de la producción de El Trampal se alejaba bastante de la ubicación del taller, apareciendo en Mérida y en su territorio. Esta propuesta se debilita para Melque por la semejanza de ambas producciones y por la ausencia de referencias concluyentes con los centros toledanos pues se desconoce escultura como la de Melque fuera de su lugar y a qué edificios pertenece la aparecida en la ciudad de Toledo, aunque en ella se hayan encontrado piezas similares a las de los conjuntos de Guarrazar y Sonseca-Orgaz (El Trampal: Cruz 1985: n. 155 y 157; Caballero y Sáez 1999: 169171; Mateos 1999: 168 y 175, n. $\left.{ }^{\circ} 44\right)$.

El uso, la forma y la técnica a bisel de las piezas de mobiliario litúrgico (de canceles, largueros y placas, y de altares) que sirven estos talleres dependen de la tradición local tardoantigua. Pero se diferencian de ellos especialmente en que su estilo, esquemas y motivos han asimilado patrones decorativos sirio-omeyas. Es el mismo sistema de cierre empleado en las iglesias tardoantiguas, pero preparado para una arquitectura que no lo había previsto, cuyos estrechos espacios, debido a la estructura abovedada, obligan a utilizar placas singulares y provocan una sensación de obstrucción y ruptura espacial distinta a la que producía su utilización en las antiguas iglesias basilicales. Pero estos cierres eran necesarios en las nuevas iglesias por mantenerse una liturgia en este sentido similar. De modo parecido, Sastre de Diego observa en la composición decorativa de los altares (Fig. 5.1; de forma tradicional, con un ara central y cuatro columnitas) una evolución compositiva y cronológica con respecto a las que sirven de modelo durante el siglo VII en Mérida y Toledo (Patrones, Cruz 1985: 428-429; Caballero 1994-95: 340-341; Caballero y Sáez 1999: 171-173; aras, Sastre de Diego 2009: 573; prototipos toledanos, Barroso y Morín de Pablos 2007: n. ${ }^{\text {ss }} 27-30$ ).

La reutilización de material es una característica de ambas marmolerías, que acapararon mármol romano con una doble finalidad, aprovechar piezas directamente (fustes y capiteles) y conseguir material para sus nuevos trabajos de taller. De este modo se mezclaron en estas iglesias decoraciones antiguas y modernas, ambas suministradas por los mismos talleres (Utrero y Sastre de Diego 2012, en los siglos VIII-X).

Desconocemos las características de las columnas del arco del ábside de la iglesia de Melque porque fueron arrancadas con cuidado para ser reutilizadas por segunda vez, lo que sugiere la importancia de las piezas por su material y forma. También el material de mármol para realizar piezas decoradas procedía de expolio como demuestran el larguero de cancel, tallado en una pieza sacada de un fuste de columna de gran diámetro, y el tondo citados (Columnas: Caballero y Latorre 1980: 593-594).

El taller que sirvió a El Trampal actuó del mismo modo. Los capiteles procedían de expolios de edificios romanos ${ }^{4}$ y también los fustes, aunque de ellos no han perdurado restos. Los de fustes de pilastras, tallados en granito, se deben considerar síntoma de la escasez de los de mármol expoliados o del desconocimiento técnico de cómo tallar nuevas piezas cilíndricas. Además, la materia prima para tallar las piezas decoradas también procede de expolio romano, como demuestra que algunas piezas de impostas y cimacios conserven aún superficies y molduras de la utilización originaria y las diferencias en las formas y dimensiones de las

\footnotetext{
${ }^{4}$ Agradezco a Antonio Monterroso, CCHS-CSIC, la adscripción genérica de estos fragmentos: por su estado "solo se les puede atribuir una datación imperial", por su material y lugar de hallazgo "se puede apuntar una datación a partir de finales del s. I d.C. o inicios del II. Un fragmento presenta un esquema probablemente corintizante" y "el otro, un kalathos decorado con un motivo liriforme. Quizás pertenecen a un taller local-regional". Referencia general para los capiteles "corintizantes" en Gans 1992.
} 
placas de los canceles y largueros. (Caballero y Sáez 1999: 119-128, equivocados al suponer un capitel altomedieval; fustes, Utrero y Sastre de Diego 2012).

FUNCIÓN CONSTRUCTIVA DE LAS IMPOSTAS FORMADAS POR FRISOS O MOLDURAS

La principal función de los frisos de la iglesia de El Trampal fue la de imposta de bóvedas recorriendo el interior de los ábsides, "transepto" y coro (Figs. 1, 6.1 y 7.1-3). Aunque han sido arrancados de su sitio se reconoce su recorrido por el hueco relleno y la permanencia in situ de tres fragmentos en los ábsides norte y central. Su decoración de trenzas con botones hace suponer que todas las impostas se decoraron con este tema, el más repetido en los fragmentos conservados. Estas impostas se interrumpían por los cimacios de las semi-columnas de las embocaduras del ábside y las columnas de los arcos del "transepto" (cada grupo con distintos material y motivos), reconociéndose la diferente función que tenían las impostas de bóveda, en el muro, y los cimacios de los arcos, sobre columnas (Caballero y Sáez 1999: 97-107 y 122-124).

Tanto las impostas de bóvedas como los cimacios de columnas tienen la función de conseguir un remate plano y uniforme de los muros o de las columnas donde apoyar las cimbras y el arranque de las bóvedas o los arcos. Esta función se cumple solo aparentemente en El Trampal como demuestra que todas estas piezas e incluso las columnas hayan sido arrancadas y robadas posteriormente sin que en ningún caso bóvedas o arcos se resintieran de su falta de apoyo, demostrando que constructivamente son independientes y que el carácter de impostas y cimacios es decorativo (Figs. 1.2-3 y 7.1-3). La arquitectura estaba preparada para resistir sin que la decoración o las piezas reutilizadas y exentas (capiteles y fustes) cumplieran la función estructural que representan. La misma característica presenta la arquitectura de La Nave. Para ello, los salmeres de arcos y bóvedas estaban construidos de modo que "enjarjaban" profundamente en el muro (volando los arcos del "transepto") impidiendo que el edificio se arruinara mientras que no partieran (Caballero y Sáez 1999: 96-97; Utrero 2006: 147-148).

Como excepción, la imposta adopta una función distinta a la aparente de arranque de las bóveda cuando recorre el testero de los ábsides. Lo hace dada su escasa longitud e influida por la situación de la ventana, cuya bovedilla también la necesita, y al coincidir en altura con la de la bóveda del ábside. No ocurre lo mismo en los testeros del "transepto", donde las ventanas y, por lo tanto, sus líneas de imposta se encuentran más altas. De un modo orgánico, cuando están a la misma altura, la imposta de las bóvedas sirve como imposta de las bovedillas de las ventanas, decorando sus jambas y rematando en los paramentos exteriores. El hecho de decorar las jambas de las ventanas y salir a los paramentos se convierte en una norma. La imposta de las bóvedas también se detiene al llegar a las cabezas de las perdidas pilastras de las arcadas del aula y, en los muros occidentales del "transepto", al tropezar con los arcos de descarga de las puertas laterales. En estos paramentos de las puertas (que son los occidentales de las torres o cimborrios laterales) deja de actuar como imposta de bóveda para hacerlo como friso decorativo (Caballero y Sáez 1999: 124).

En El Trampal también poseyeron impostas los arcos de las puertas laterales (hueco en la puerta occidental del porche norte), actuando del mismo modo que el descrito en las ventanas. Estas puertas se pudieron decorar con el mismo tema de trenza o con alguno de los otros conocidos, trifolios, roleos, seudo-roleos (círculos tangentes con racimos y hojas alternando) y trenzas con flores, cuyo exacto acomodo se desconoce. Otra pieza de mármol, descontextualizada, decorada en dos caras perpendiculares con cintas y botones puede considerarse que, por su forma y altura algo mayor, funcionara como capitel o cimacio quizás de las pilastras de las arcadas del aula (Caballero y Sáez 1999: figs. 48, 78 y 79).

En la iglesia de Melque, sencillas molduras de granito (no frisos) cumplen la función de imposta de bóvedas y arcos, en el interior, y de cornisa en el remate de los paramentos externos (Figs. 2 y 7.4). Fuera y dentro se colocan a tres y cuatro alturas distintas, marcando los paños de los muros; en el interior desde la más baja, en los pasos abiertos en el frente oriental de la nave de "transepto", hasta la más alta, en el arranque de la cúpula del crucero. A pesar de su mayor complejidad, el esquema es similar al que siguen los frisos en el interior de la iglesia de El Trampal. Ambas iglesias coinciden en utilizarlas para las ventanas o los huecos de paso, estén o no a la misma altura que las de las bóvedas, doblándolas al exterior si no lo están y conservándolas en los testeros cuando existen ventanas a su altura. Se diferencian en que en Melque es moldura (preparada para soportar la decoración de estuco), mientras que en El Trampal es friso decorado y no existe la cornisa exterior.

Garen, al estudiar Melque, señaló este tema como característico de las iglesias que considera visigodas. El friso (imposta) equilibra las masas arquitectónicas interiores, se relaciona con las ventanas aprovechando su hueco para salir al exterior, y, cuando se independiza, arrastra y mantiene un fragmento. Se refiere a 

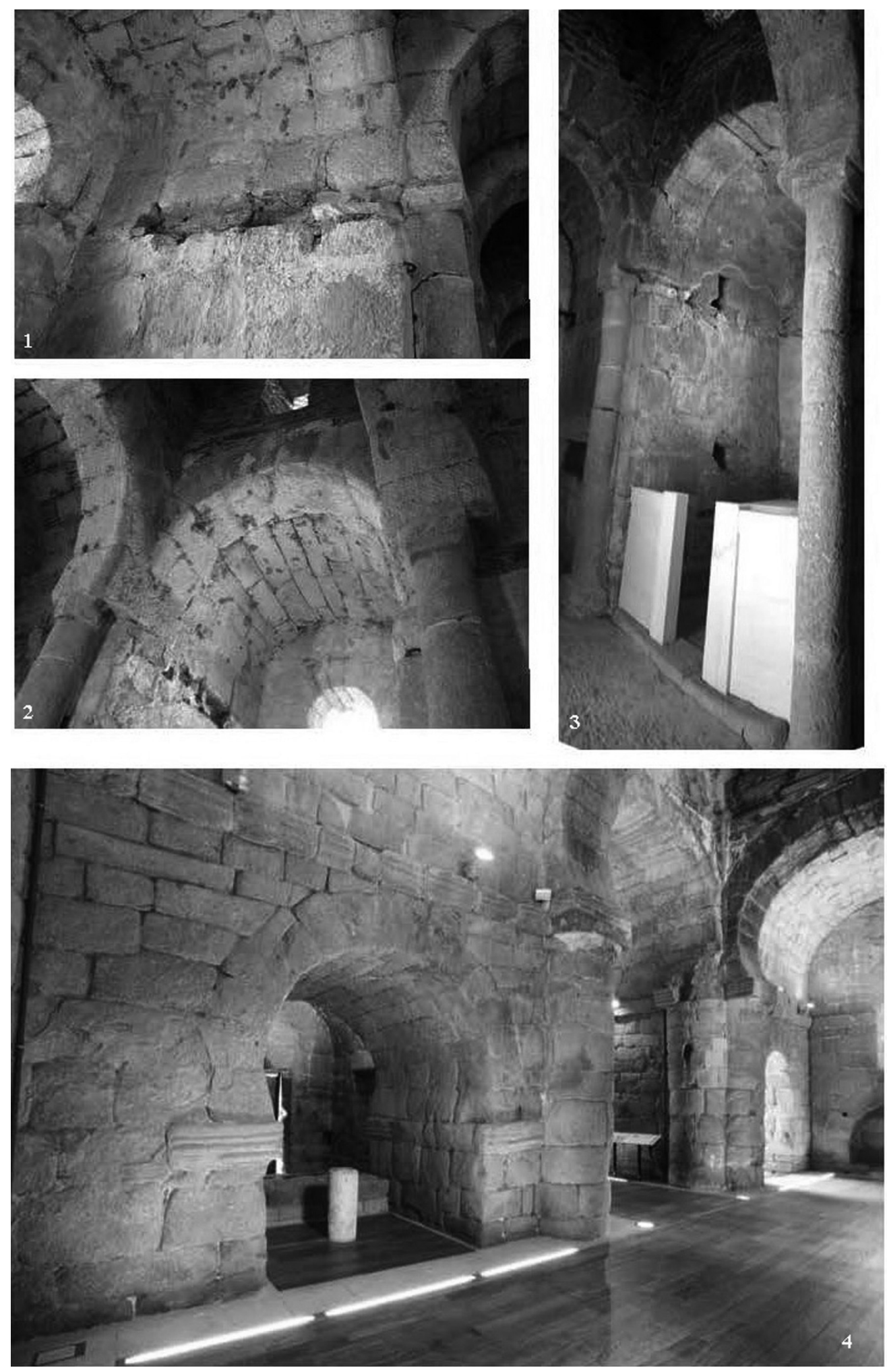

Figura. 7. 1 a 3. Ábsides y "transepto" de El Trampal. 4. "Transepto” de Melque. 
las iglesias de La Nave, Marmelar y Baños, de modo que Melque continuaría y desarrollaría en el siglo VIII el sistema visigodo. Gómez-Moreno citaba las "fajas de adorno... en impostas y como frisos" que diferencian la tradicional arquitectura "paleocristiana" de la innovadora y orientalista "visigoda" (Gómez Moreno 1966: 117, 119-120 y 123; Garen 1992: 300-301).

La estructura constructiva de El Trampal presenta un estadio evolutivo más avanzado que la de Melque, al olvidar la función básica de estas piezas, a la vez que facilita el ahorro del material de mármol y la solución de posibles fallos de resistencia de las piezas reutilizadas. Sin que ello suponga una diferencia cronológica, pero sí de filiación.

\section{LA INTRODUCCIÓN DE "FRISOS" CONSTRUC- TIVOS EN LOS CENTROS DECORATIVOS DE MÉRIDA, CÓRDOBA Y TOLEDO}

La integración de frisos decorados como imposta en la obra arquitectónica corresponde a una nueva producción abovedada, aparecida en un momento posterior al año de referencia 711. Consecuente con esta propuesta, repaso su presencia en los tres centros principales de la considerada decoración "visigoda", Mérida, Córdoba y Toledo. Hasta el descubrimiento de El Trampal se desconocían estas impostas en los centros decorativos de Mérida y Córdoba, situación que resaltaba con la de Toledo donde comparativamente son abundantes, como señalaba Cruz Villalón (1985: 262-263): "Sorprende en Mérida la ausencia casi total de frisos decorativos contrastada con la riqueza de las iglesias del siglo VII... ¿Quiere esto decir que las iglesias visigodas de Mérida tuvieron un sistema ornamental bien diferenciado de las iglesias del Norte, incluido Toledo? El contraste cuantitativo advertido sería quizá el más evidente para hacer tal afirmación".

Se puede completar la distinción geográfica con la cronológica, diferenciando el sistema ornamental de los edificios del siglo VII del de los abovedados de los siglos VIII al X. Entonces, la ausencia de frisos/ impostas en Mérida y Córdoba obliga a rechazar su supuesta afinidad con el centro de Toledo (Balmaseda 2007: 280 achaca la diferencia a cronologías de la segunda mitad del siglo VI y siglo VII).

De las diez piezas posibles de Mérida (una dada como friso y las demás como cimacios dudosos) solo tres se pueden considerar impostas. Una de ellas (Cruz 1985: no 357, roleo) pertenece al taller que decoró la iglesia de El Trampal y es posible que proceda de esta misma iglesia. Otra de las piezas (Cruz n 356, trifolios, de Pan Caliente) se decora con un tema sim- plificado de la serie de El Trampal. La tercera (Cruz $\mathrm{n}^{\circ} 355$, rombos) no tiene paralelo con la temática de El Trampal y se puede relacionar con una pieza de Córdoba. A estas piezas del catálogo de Cruz hay que añadir las ya vistas del taller de El Trampal y la imposta del ábside central de la basílica de Santa Eulalia de Mérida decorada con cuadrifolios que encierran botones. Mateos sitúa esta en un recrecido que supone del mismo momento que las torres añadidas sobre los ábsides laterales por el obispo Fidel entre 560 y 570 d.C. (según las "Vidas de los Padres de Mérida"), aunque no existe una relación directa entre ambas obras. Evidentemente, la datación propuesta es posible, aunque en la basílica "eulaliense" aparecieron piezas decorativas que pertenecen al taller de El Trampal, para las que Cruz ya sugirió "un posible avance de fechas a la etapa post-visigoda", por lo que es posible que esta restauración del ábside central corresponda a una fecha más avanzada (piezas primera y segunda: Caballero y Sáez 1999: n ${ }^{\text {os }} 21-22$ y 19-20, fig. 63; ábside Santa Eulalia: Mateos 1999: n. 403, figs. 32-34; Santa Eulalia y El Trampal: Cruz 1985: 428-429, n ${ }^{\text {os }}$ 155-158; Caballero y Sáez 1999: $n^{\text {os }} 23$, 43, 48 y 49, figs. 63 y 67; Mateos, 1999: $\mathrm{n}^{\text {os }} 44$ y 80).

De las seis piezas de Córdoba dadas como frisos, solo dos son impostas (Sánchez Velasco 2006: $\left.\mathrm{n}^{\text {os }} 35-40\right)$. La $\mathrm{n}^{\circ} 39$, con rombos, recuerda la tercera de Mérida y ambas podrían ser, dentro de su sencillez, de cronología avanzada. La $n^{\circ} 38$, de Cercadilla, presenta cuadrifolios que encierran alternativamente una cruz y un botón, elementos característicos de los ambientes técnicos de Toledo (Fig. 5.1, Melque) y Mérida (El Trampal).

Falta por ver el caso distinto de Toledo y su territorio, donde la presencia de impostas y cimacios es mucho más numerosa. De las 90 piezas conocidas en la ciudad ${ }^{5}$, el grupo más numeroso (56 piezas) es el de las decoradas con cuadrifolios, con sus varian-

\footnotetext{
${ }^{5}$ El reciente catálogo de escultura decorativa de Toledo (Barroso y Morín de Pablos 2007), contiene piezas pertenecientes a diferentes periodos. En las 193 piezas catalogadas como "frisos", $n^{\text {os }} 62-251$, en las que se incluyen las impostas y cimacios, se diferencian los siguientes: Tardorromano: 14 piezas, $\mathrm{n}^{\text {os }}$ 200-213; Islámico, del s. X y Mudéjar: 53 piezas, ${ }^{\text {os }} 112,119-149,164-165,168-170,174-175,179-181$, 185, 238, 241-248; el $n^{\circ} 244$, prototipo con modelo en Khirbat al-Mafjar y paralelo en Escalada según Schlunck (1965: 923, fig. 5); abundantes paralelos cordobeses en Pavón 1990: Altomedieval: 10 piezas, $n^{\text {os }} 186-194$ y 429 , técnica de plano excavado como el grupo anterior, piezas similares en Tábara (Zamora) consideradas asturianas por Gómez-Moreno (1927) y Regueras y García-Aráez (2001: 37, fig. 33); Modernas: una pieza, $n^{\circ} 216$; Indeterminadas: 23 piezas, $n^{\text {os }} 67-72,82,84,98$ 99, 102, 117-118, 171, 195, 198-199, 214, 218-219, 234, 237, 251; visigodas o emirales: las 90 piezas restantes, a las que se pueden añadir dos más fuera de grupo, $n^{\text {os }} 432-433$. Además, dos piezas son largueros y no frisos, $\mathrm{n}^{\text {os }} 215$ y 249 .
} 
tes. El tema coincide con el visto en la imposta del ábside de Santa Eulalia de Mérida. Pero si añadimos a las piezas de la ciudad las de su territorio, el tema más repetido es el de los roleos que predominan en los yacimientos de Guarrazar y la zona de Sonseca y Orgaz (roleos: Balmaseda 2007: especialmente 282295, figs. 5, 8, 9, 11 y 15).

El tema general del roleo se corresponde en los talleres toledanos y en el de El Trampal, aunque difieren sus variantes locales, roleos con la llamada "palmeta bizantina" en los toledanos y roleos con "botones" en el extremeño. Acompañan además otros temas, la simplificación del roleo convertido en círculos tangentes, las cintas con botón central y los cuadrifolios con botón o cruz inscrita que reconocemos como variantes en lo ya visto de Córdoba y Melque y también, con sus variantes locales, en El Trampal (Caballero y Sáez 1999: $n^{\circ} 23$ ).

Los motivos llamados por Gómez-Moreno "tulipanes" o "capullos" y por Schlunk "palmetas bizantinas" en realidad representan, de modo estilizado, un racimo de uvas con dos pequeños círculos en su base como sarmientos (Fig. 8.2, 3 y 5). Según variante de taller, la representación de los frutos se efectúa mediante botones (Guarrazar) o mediante trazos angulosos (La Mata, quizás representando otro fruto o flor). En el roleo, los racimos alternan con las hojas (trifolios), de modo que aquellos cuelgan y estas se yerguen. En ocasiones se pierde el racimo permaneciendo los circulillos, esto es, los sarmientos, y desaparece la alternancia con las hojas (Los Hitos I y Arisgotas II). Aparte de su relación con los frisos de Bande y La Nave, desde Schlunk se relaciona la "palmeta" con los eslabones de la cadena de la corona de Suintila aparecida en Guarrazar, pero no hay entre ellos una vinculación directa, aparte de la dificultad de que temas escultórico y de orfebrería se relacionen productivamente como se pretende. Mejor que al aparente paralelo de Guarrazar, se asemeja a la decoración de la redoma de vidrio de Astorga, fatimí o española del siglo X. El "racimo toledano" se debe relacionar también con el que Hoppe denomina "racimo con borde", un listel en forma de hoja o corazón relleno de botones o "granos" (Figs. 5.1 y 6.1 y 2, Melque, El Trampal y Sta. Eulalia). Ambos son variantes de un mismo tema y pertenecen a un mismo horizonte. Este autor supone el "racimo con borde", mejor que una "práctica de taller", una moda homogénea geográfica y cronológica, propia del siglo IX, en relación con el grupo de El Trampal (Santa Eulalia de Mérida) y, en conclusión, motivo que debería "incidir de un modo significativo en la revisión del corpus de la escultura visigótica". Los roleos toledanos se completan con las "ligaduras" o "anillos de fijación" que para Hoppe son indicio de realismo, significado de "jardín" y "procedencia oriental e islámica". Un análisis más detallado podría encontrar más relaciones entre el taller extremeño y los toledanos, como por ejemplo las hojas de cinco lóbulos que rellenan los roleos en El Trampal, las de tres lóbulos y dos hojillas de base en Guarrazar y las palmetas de una imposta de La Mata (Figs. 6,1-2 y 8,1) ("Palmeta bizantina": Schlunk, 1947: 266; Gómez-Moreno 1966: 122; Id. y Hauschild 1978: 99; repertorio de los yacimientos toledanos y coronas de Guarrazar: Balmaseda 2007: 286 y 297-298; redoma de Astorga: Gómez-Moreno, 1919: 376, fig. 207; Hoppe 2004: Guarrazar, 349, $\mathrm{n}^{\text {os }}$ 60 y 61 ; racimo con borde 348-351; "ligaduras" 360363. Hojas de lóbulos: Caballero y Sáez 1999: n²3; Balmaseda 2007).

$\mathrm{Ni}$ en la ciudad de Toledo ni en su territorio de Guadamur y Sonseca-Orgaz tenemos elementos que sirvan para relacionar producción arquitectónica y decorativa. Los lotes de frisos no tienen contexto conocido ya que sus piezas están reutilizadas como ocurre con las de San Pedro de La Mata (Casalgordo, Sonseca) y con las que decoran los contrafuertes del edificio de Los Hitos (Arisgotas, Orgaz). Además estos edificios plantean problemas de comprensión. El ábside y la parte occidental del de La Mata son restauraciones y la organización del de Los Hitos recuerda más un edificio residencial que una iglesia. Sin embargo se puede asegurar la función de imposta de sus frisos y su cantidad predice la existencia de un número significativo de edificios abovedados, incluso en la propia ciudad de Toledo de donde procede un grupo de frisos con "palmetas bizantinas". Otras piezas decoradas con temas escasamente representados, como círculos tangentes, imbricaciones, rombos y trifolios, pudieron tener la función de impostas de arco (La Mata: Utrero 2006: 521-522; Los Hitos: Balmaseda 1998: vol. II, láms. LH21y226; Moreno 2003/2004: 68-70).

Para comparar las producciones decorativas de Mérida y Toledo solo tenemos un taller emeritense, el que sirve a El Trampal, que forme parte con seguridad de estas producciones avanzadas que se distinguen por la presencia de impostas decoradas. Las aparentes diferencias entre estos centros se desdibujan en un ambiente común. Salvando las de cantidad y temática específica, se asimilan la técnica, el estilo y la forma, la cronología $\mathrm{y}$, especialmente, la función constructiva y decorativa. Dada la semejanza entre las piezas de ambos grupos decorativos, la producción toledana debió proceder, como he propuesto para la de El Trampal, de un taller

\footnotetext{
${ }^{6}$ Agradezco a Luis Balmaseda el conocimiento de su texto inédito.
} 

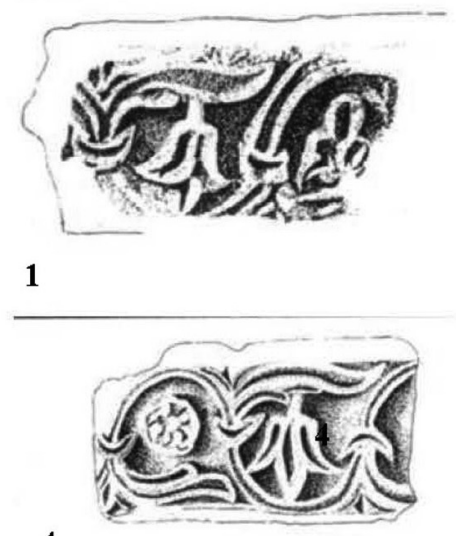

4
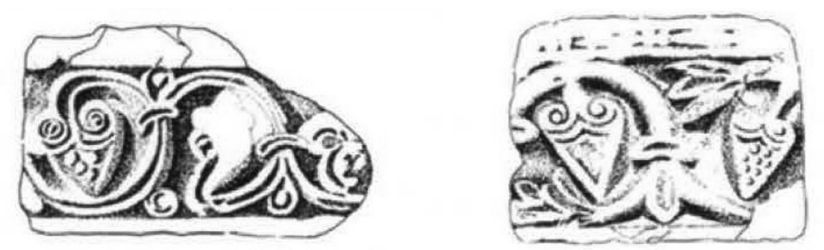

2

3
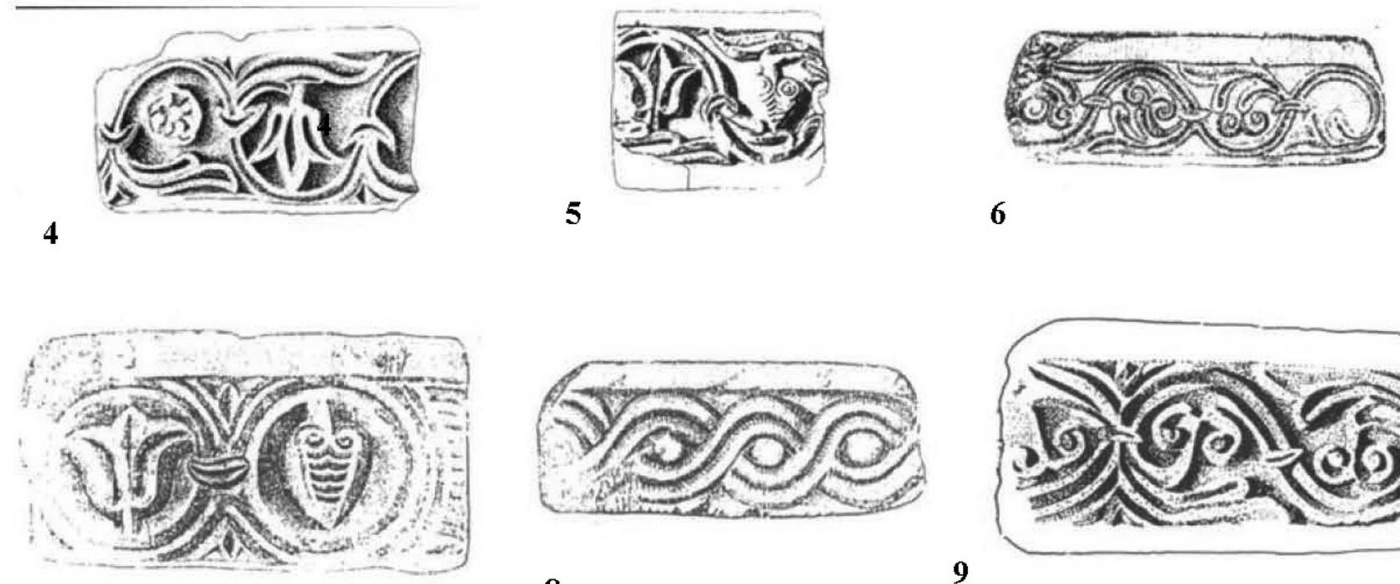

7
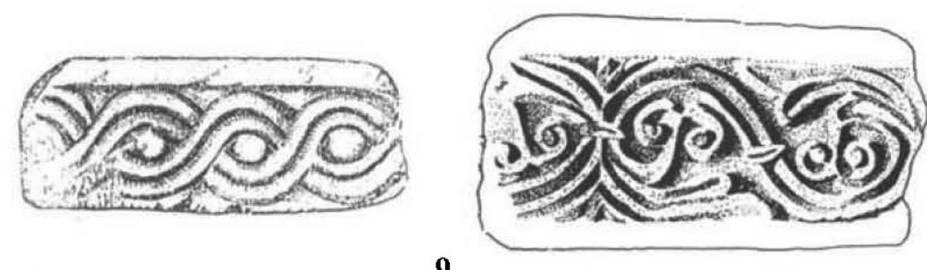

8

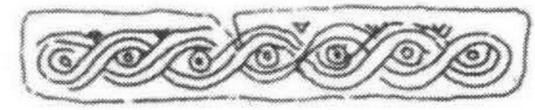

11

10

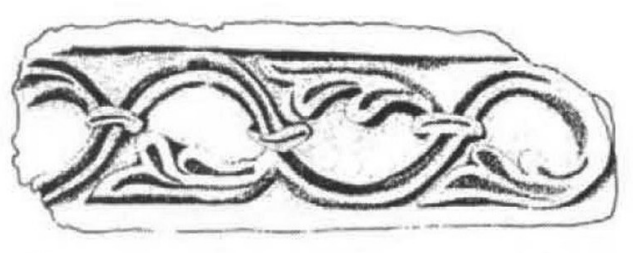

13

Figura 8. "Frisos" del grupo de Guarrazar y Sonseca-Orgaz (Toledo). 1 a 4. Guarrazar. 5 a 8. San Pedro de La Mata. 9 a 11. Los Hitos. 12 y 13. Arisgotas. Balmaseda 2007. 
urbano que las serviría para que se acoplaran al espacio arquitectónico previamente preparado.

La abundante cantidad de impostas en Toledo frente a las escasas de Mérida puede corresponder a una mayor producción constructiva en la sede toledana de edificios abovedados y decorados (iglesias). Pero este déficit productivo lo compensan los edificios emeritenses que no están decorados ni, al parecer, abovedados (residencias), lo que puede indicar diferencias en la composición de promotores y usuarios. Las obras realizadas en Santa Eulalia, en la ciudad de Mérida, nos permiten imaginar cómo serían los edificios de la ciudad de Toledo (decorados en ambos lugares con impostas con cuadrifolios), y, del mismo modo, el edificio de El Trampal, en el territorio de Mérida, ayuda a comprender los del territorio toledano (edificios emeritenses: Alba 2007: 179-189).

Cabe aún hacer otra observación sobre las producciones decorativas de Mérida y Toledo. La producción decorativa litúrgica (canceles) del taller de Melque queda aislada de la de su territorio toledano tanto por no existir en estas referencias para su temática (sin embargo similar a la del taller de El Trampal), como por la ausencia de piezas de canceles. Puede que en Toledo no existiera una tradición tardorromana lo que obligaría a que Melque recurriera a la producción extremeña. A su vez escasean los indicios de canceles en el territorio toledano, reducidos a las huellas para su encastre en el edificio de La Mata, un larguero de Guarrazar y una placa de Los Hitos (larguero y placa: Balmaseda 2007: figs. 7c y 13).

\section{SAN JUAN BAUTISTA DE BAÑOS (PALENCIA)}

El taller escultórico de Baños utilizó una amplia y seleccionada colección de piezas decorativas, de las que unas son reutilizadas, de carácter constructivo (cimacios e impostas), y otras creadas ex novo por el taller de escultura, constructivas (frisos, cornisas y ajimeces) y de mobiliario litúrgico (canceles).

El grupo reutilizado tiene una trascendencia historiográfica ya que el modelo explicativo "visigotista" consideraba que sus temas decorativos eran prototipos del arte visigodo, datados por la inscripción de la iglesia que conmemora una dedicación del rey Recesvinto en el año 661 d.C. Al demostrar la lectura arqueológica del edificio que la mayoría de esta escultura, supuestamente prototípica, era reutilizada planteé que la inscripción también pudo serlo y que no fuera coetánea al edificio. Recientemente se ha considerado que su epigrafía es altomedieval y por lo tanto la inscripción, una copia o un falso de época (Caballero y Feijoo 1998: 237; Hoyo 2006).
Este grupo reutilizado se compone de dos series. La primera está formada por fustes, basas, capiteles y cimacios moldurados y decorados (imbricaciones y estrellas) de época tardorromana, visigoda, que se utilizaron en las arquerías del aula (Fig. 10.1) (Palol 1988: fotos en 45-46 y 48-50).

La segunda serie reutilizada la forman frisos, unos decorados con cuadrifolios (en dos variantes), "ojos de gato", trifolios y contarios, utilizados como imposta en el ábside central; y otros, con cintas y "ojos de gato", en los ábsides laterales. Esta serie es de un estilo diferente a la de los cimacios de la primera serie, y de procedencia y cronología distinta (Fig. 10.2). En su función anterior, las piezas de imposta con cuadrifolios del ábside central se usaron (o se iban a usar) emparejadas, con sus extremos doblados y decorados, en vanos abovedados (ventanas o pasos), en una posición parecida a la de pasos orientales del "transepto" de la iglesia de Melque (Fig. 7.4). Los extremos decorados de cada pareja se definen por medio cuadrifolio con un trifolio o una punta en su centro (según las variantes) que sustituye a un "ojo de gato". Así se diferencian cuatro parejas expoliadas (equivalentes a dos vanos) de una variante y tres parejas (un vano y medio) de la otra. En las impostas con trenzas de los ábsides laterales, el remate en redondo de la trenza debe indicar el extremo de cada unidad reutilizada, aunque no he podido determinar la longitud a que corresponden ni su número. Quizás procedan de un edificio asimilable al grupo de El Trampal y Melque, de cronología post-visigoda no demasiado anterior a la de Baños ${ }^{7}$. El ajuste de las piezas, que poseen ligeras variaciones de altura y están descantilladas, a la sillería de los muros la efectuaron los canteros a pie de obra (cuadrifolios: Palol 1988: 53).

También las arquivoltas del arco del santuario y del arco del porche y la cornisa interior y el friso exterior de la nave central del aula proceden de acarreo y pertenecen a esta segunda serie. La arquivolta del santuario no completa su recorrido sobre el arco hasta llegar a la imposta y se corta rudamente para adosar a los muros de las arquerías del aula, al tener la misma luz el ábside que la nave central. En el porche, la arquivolta no voltea el arco por completo, formando cuerpo con las dovelas pero independizándose de los salmeres; hay dovelas cuyo trasdós es recto en vez de seguir la curva del arco; y la decoración no encaja entre las dovelas. Tampoco ajustan las piezas de la cornisa que remata el interior de los muros de la nave central (arquivoltas: Palol 1964: lám. XV; Id. 1988: figs. en 54 y 55; Caballero y Feijoo 1998: fig. 18).

\footnotetext{
${ }^{7}$ Pero también la relación entre los repertorios de Toledo, Baños y La Nave puede encerrar una filiación de sus talleres.
} 

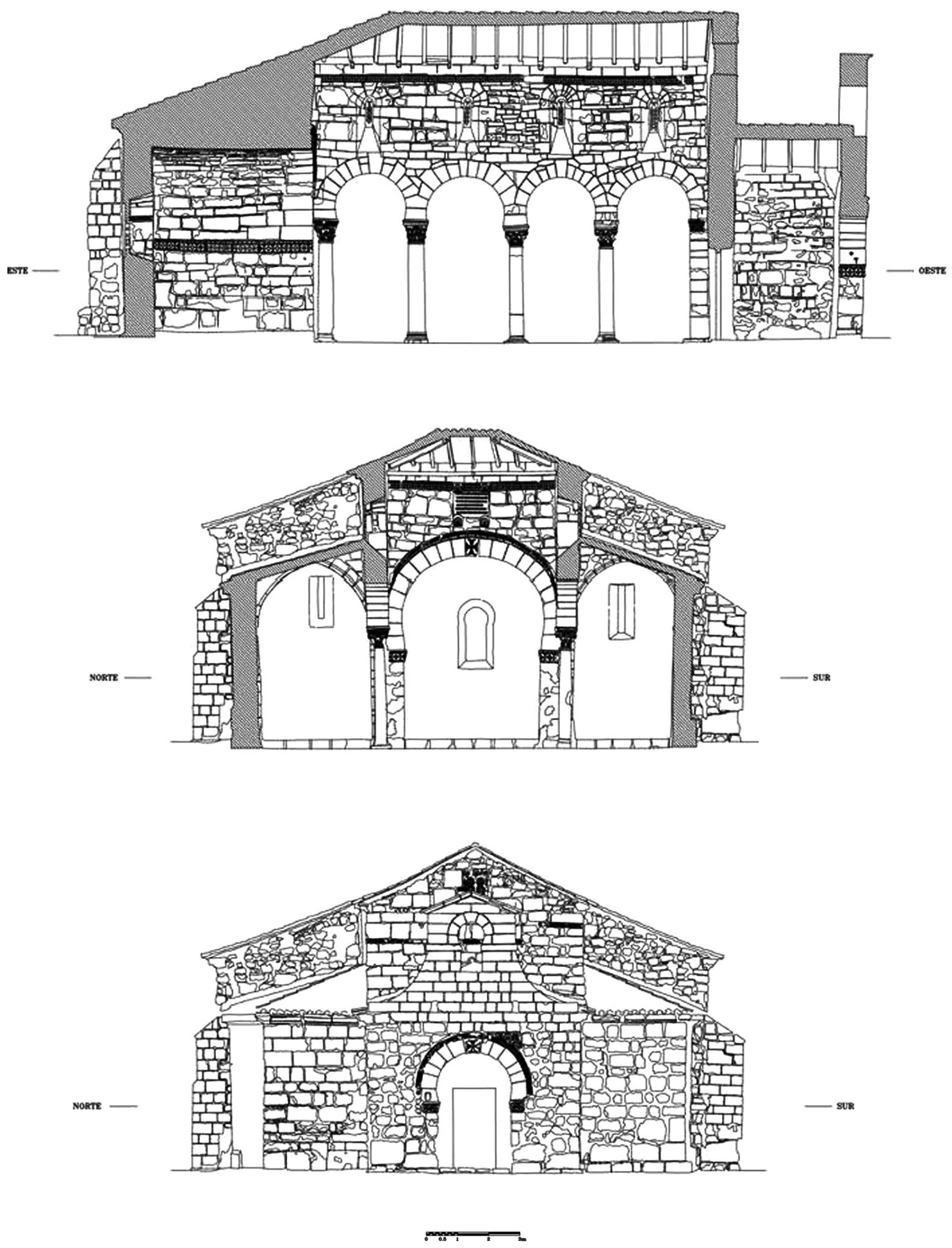

Figura 9. San Juan Bautista de Baños (Palencia). Secciones longitudinales a sur y este y alzado oeste. Caballero y Feijoo 1998. Escala $1 / 150$. 

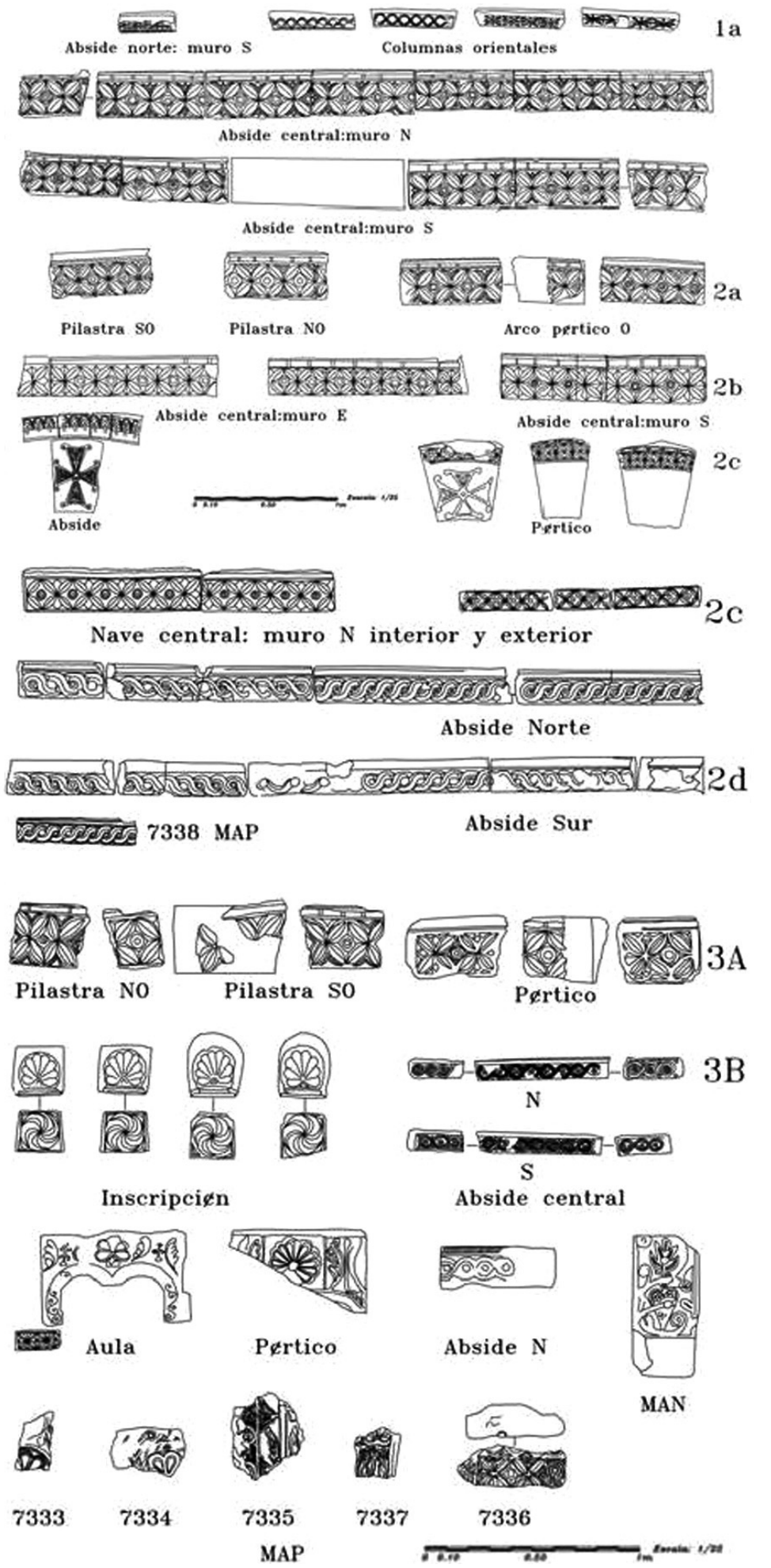

Figura. 10. Decoración de Baños. Grupo 1, cimacios visigodos reutilizados. Grupo 2, impostas y frisos reutilizados. Grupo 3, impostas, modilllones, ajimeces y placas y larguero de canceles fabricados ex profeso para el edificio. Caballero y Feijoo 1998. Escala 1/44. 

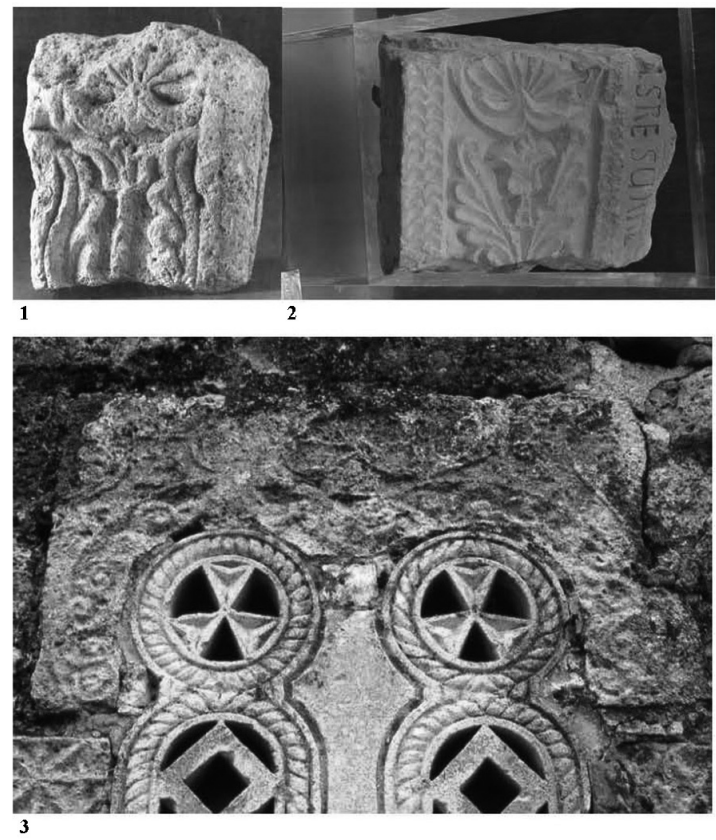

Figura. 11. Baños. 1 y 2. Larguero de un cancel (Palol 1988) y marco de la inscripción del Credo, Vega Baja de Toledo (Museo de la Cultura Visigoda). 3. Ajimez occidental del aula.

El grupo de piezas talladas ex novo por los escultores de Baños incluye, por una parte, el relabrado imitativo de las impostas que se reajustaron en las pilastras occidentales de las arcadas del aula y en las jambas del arco de entrada del pórtico; y, por otra, la realización nueva de las impostas de la ventana del ábside del santuario, los canecillos o modillones que sujetan la inscripción, los ajimeces de la nave central (Fig. 11.3) y los canceles litúrgicos (Fig. 10, grupo 3 ). De los canceles solo se conocen fragmentos de dos largueros y tres placas. Sus temas decorativos son típicas veneras y hojas digitadas, molinillos, palmetas, trifolios, racimo con borde, pámpanos y sencillas hojitas. Es significativo del estilo del taller de Baños su falta de carácter orgánico, como se ve en el modo en que se añaden los motivos a las ramas de los roleos y a los junquillos de los temas a eje o de los marcos o incluso la manera en que las hojas digitadas se aíslan por completo (canceles: Palol 1964: 14-24; Id. 1988: figs. en 59-66. Impostas relabradas, Id.: fig. en 40).

Tanto los temas del material reutilizado como los del nuevo se relacionan con el repertorio más avanzado de Mérida, Toledo y las iglesias del Duero y Asturias (Fig. 11.1 y 2), neutralizando en principio el valor que pueda tener el estudio de su estilo. Pero el que interesa es el repertorio decorativo empleado en las piezas de la serie nueva porque data el momento de construcción del edificio, aunque se demuestre que su cronología se acerque a la de las piezas de la segunda serie reutilizada. La imposta con trenza y botones de la ventana del ábside es similar a la imposta de El Trampal. El tema a eje con dos hojas digitadas y una venera de un larguero se relaciona tan directamente con el mismo tema del epígrafe del Credo de Toledo que se ha considerado también prototipo visigodo, sirviendo para fechar la escultura toledana por la inscripción de Baños, sin tener en cuenta entonces las dudas que la estratigrafía arquitectónica pudiera verter sobre su datación. La aparente relación de la temática decorativa de Baños con la del centro de Toledo, se puede parangonar con la que encontramos entre la de Melque y el centro de Mérida (larguero y Credo de Toledo: Jorge 1957; Schlunk 1970: 181 ss., taf. 54 ss., enlazan con La Nave, Lisboa y Quintanilla; Palol 1988: 63, fig. en 62; Caballero y Feijoo 1998: 228-229).

En la construcción de Baños se empleó mayoritariamente material reutilizado. Así son al menos algunos de sus sillares, piezas de forma, como las dovelas del arco del santuario, y una parte importante de su escultura. Los canteros ajustaron a pie de obra tanto la sillería como las piezas decoradas, acarreadas por los escultores, sin preocuparse del encaje de sus temas decorativos, ni de cómo interferían con los elementos constructivos (arquivolta cortada por las arquerías; friso del ábside cortado por la ventana u oculto en las esquinas). Los escultores también relabraron a pie de obra algunas piezas (cimacios del arco del porche y de las pilastras occidentales de las arquerías). Y utilizaron como materia prima material de expolio para tallar las piezas nuevas de los canceles, como demuestra una lauda romana usada para fabricar un tablero. Los canceles se trabajaron en taller y se entregaron a la obra para que los canteros los ajustaran al edificio donde la arquitectura y la liturgia lo requisieran. No se han conservado indicios del lugar que ocuparía este mobiliario litúrgico, ni tampoco se ha imaginado dónde se colocaría. El taller de escultura expoliaba, por tanto, material para usar como materia prima y material decorado para reutilizar directamente. Si nos preguntamos sobre cómo se consiguieron estos conjuntos tan diversos, debemos suponer que canteros y escultores acopiaron materiales diferentes, de procedencias y cronologías distintas, mediante un acarreo selectivo y, en el caso de los escultores, con un almacenamiento previo, que se acomodaron a un proyecto común (dovelas y sillares expoliados: Caballero y Feijoo 1998: 187 y 217-218; lauda para tablero: Id.: fig. 19, inv. 7336).

Baños se asemeja a El Trampal en el uso de material reutilizado como materia prima para la construc- 

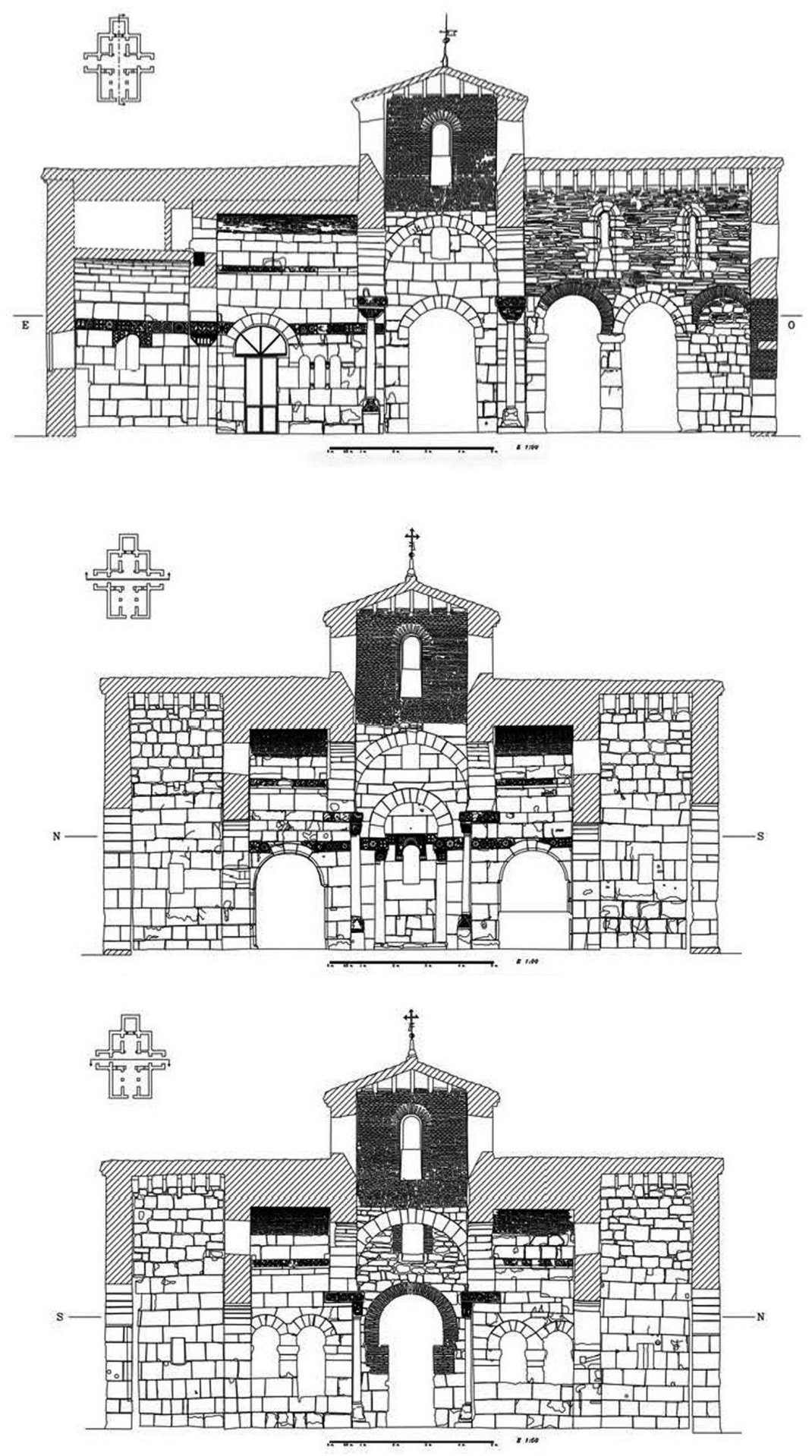

Figura. 12. San Pedro de La Nave (Zamora). Secciones longitudinal a sur y transversales a este y oeste. Caballero y Arce 2004. Escala $1 / 200$. 

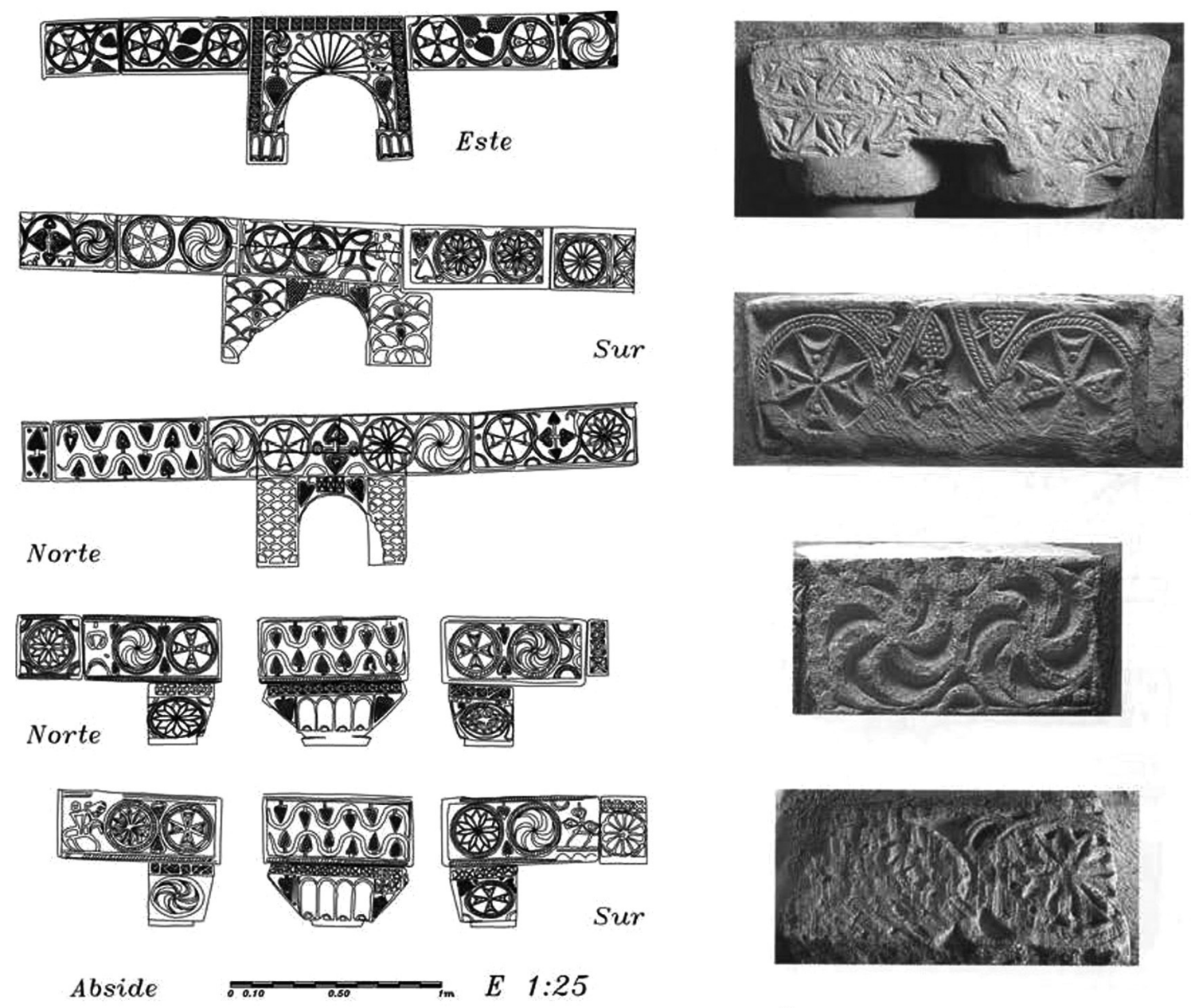

1

Figura. 13. La Nave. 1. Decoración del ábside. El sillar segundo por la izquierda del frente norte está reutilizado. Escala 1/40. 2. Piezas reutilizadas. Caballero y Arce 2004.

ción y la decoración; y, a El Trampal y a Melque en la entrega del conjunto prefabricado de los canceles. Y se diferencia de ellos en la reutilización de la mayor parte de la escultura decorativa y en la presencia de los escultores a pie de obra, al menos para relabrar algunas piezas.

Los frisos característicos y las molduras de Baños se organizan de acuerdo con el espacio arquitectónico, sus elementos y su función: impostas de bóvedas y arcos, arquivoltas de $\operatorname{arcos}$ y cornisa y friso de paramentos. En el ábside central, la imposta de la bóveda dobla por el frente de su arco (que da al aula) como si se tratara de un vano arcuado o abovedado, del modo que hemos visto en las ventanas y los vanos de El Trampal y Melque. La bóveda actúa como un vano al no poseer un arco de triunfo, diferenciado y soportado por columnas, que sustituyera su testa. En la nave central, la cornisa interior aparenta soportar la armadura de la cubierta y, en los testeros, independizada como friso, descansan sobre ella los ajimeces, y del mismo, en el testero oriental, debajo de la ventana, aparentaba colgar la inscripción supuestamente fundacional (de parecida forma a como veremos hacen las ventanas en La Nave). Al exterior, el friso, situado a media altura entre el alero de la nave central y las cumbreras de las naves laterales, actúa de fingida imposta de las ventanas. La ventana del santuario y los ajimeces de la nave central necesitan sus propias impostas, dobladas en sus frentes al exterior e interior (Baños, ajimez oriental: Palol 1964: fig. 5, dado como cancel; Caballero y Feijoo 1998: 223 y 227, fig. 19). 


\section{SAN PEDRO DE LA NAVE (ZAMORA) Y QUIN- TANILLA DE LAS VIÑAS (BURGOS)}

Los edificios de La Nave y Quintanilla, situados en la cuenca del Duero, se construyeron con sillería reutilizada, abovedados y decorados. Han llegado a nosotros incompletos, arruinada su parte occidental en La Nave y perdida por completa esta y muy arruinado el resto en Quintanilla. Tales ruinas provocan controversia sobre la forma de sus cubiertas y, si estaban abovedadas, en qué partes y con qué sistemas. Además, nos dejan sin conocer si las partes arruinadas llevaban o no decoración. La Nave, dada su construcción y su distribución arquitectónica, estaría abovedada por completo, excepto los pórticos laterales. El desconocimiento de la planta de Quintanilla dificulta más decidir su tipo de cubierta, probablemente abovedada, excepto los extremos de su "transepto" (Quintanilla: Arbeiter 1990 y 2001; La Nave: Caballero y Arce 2004; historiografía y cubiertas: Utrero 2006: 505-506 y 165-167; escultura: Caballero y Arce 2007).

La sillería de Quintanilla se supone reutilizada de una villa romana existente en el mismo lugar, aunque de tres tipos diferentes de piedra, de distintas procedencias, y reutilizando inscripciones. En La Nave, parece que el material de la sillería procede de cantera, aunque hay indicios de reutilización que plantean si todo él procedería de acarreo. En su mayoría es de arenisca, pero además se utilizó granito para la habitación occidental, zócalos y soleras, en que los indicios de reutilización son más evidentes. En ambas iglesias se reutilizan además los fustes de las columnas, pero no existe más reutilización de material ajeno, ni para convertirlo en materia prima para decorar, como se hace en El Trampal y Melque, ni decorativo, como ocurre en Baños. O se desconocían, agotados, los yacimientos de escultura o eran innecesarios por el desarrollo de talleres escultóricos, o ambas causas se asociaron. La reutilización de decoración en La Nave es solo aparente al tratarse de la "recolocación" de su propio material y, a mi parecer, de la misma obra; que pudo afectar a otras piezas no estrictamente decorativas, como a las reformadas ventanas del "anteábside" (Quintanilla: Arbeiter 1990: 396 y 402; La Nave: Caballero y Arce 2004: 124-129 y 136. Reutilización generalizada en la alta Edad Media de fustes y "recolocación": Utrero y Sastre de Diego 2012; ventanas del "anteábside": Caballero y Arce 2004: 153-155, 170-172 y 242-250).

El aparejo de ambas iglesias es de sillería, tallada y ajustada a pie de obra, con regla y sin utilizar escuadra. Esta característica es común tanto para los sillares que mantienen su cara lisa como para los que la tienen decorada.

Los cimientos de La Nave están construidos con grandes losas de pizarra (de entre 0,60 y 2 m), extraídas de las cercanías, superficialmente por capas naturales, solo desbastadas y encajadas en fosas de fundación abiertas en la roca o en la tierra virgen. Esta labor pudo realizarla una cuadrilla de albañiles, pero, dado que en el edificio solo se utiliza sillería, sin relleno de mampostería, también pudieron hacerla los picapedreros que procuraron las losas o a los canteros que le construyeron y que se responsabilizarían de colocar los cimientos y ajustar la primera hilada (Caballero 2004: 84-86, relación entre cimiento y muro figs. 44 y 45, según Camps).

Mientras que en La Nave las bóvedas se construyen por el mismo taller de cantería de los muros; en Quintanilla, talleres distintos se encargan de los muros y de las bóvedas. Las de Quintanilla (baídas del ábside, de los espacios laterales del aula y posiblemente otras perdidas, fig. 14) se fabrican en mampostería de toba caliza, explotada en cantera. Este taller de albañiles pertenece a un horizonte técnico regional que define un grupo arquitectónico burgalés/riojano/alavés por sus bóvedas similares (San Román de Tobillas 1, San Miguel de Montoria, Santa María de los Arcos de Tricio, Santa Coloma, San Felices de Oca, La Asunción de San Vicente del Valle, San Pedro de Arlanza), que mantiene la coordinación entre los talleres de sillería reutilizada y mampostería de toba, mientras que la presencia de talleres decorativos es esporádica y particular (grupo burgalés: Caballero 2001; Caballero y Utrero 2005: 183; Utrero 2006: 258-260; cronología; Sánchez Zufiaurre 2007: 267-269 ${ }^{8}$ ).

Tanto en La Nave como en Quintanilla, la decoración pertenece a dos "maestros" o dos manos distintas, por lo tanto con maneras de hacer y modelos diferentes. Se han denominado "primer maestro" y "segundo maestro" con una clara intención temporal, considerando que los edificios tuvieron dos etapas constructivas o una restauración, diferenciadas por su decoración. Sin embargo, el estudio arqueológico concluye que sus caracteres constructivos y arquitectónicos son unitarios. Ambos decoradores pertenecen a un "ambiente técnico" común y por ello coinciden en temas y en algunos detalles que confirman que pertenecen al mismo grupo de trabajo y que son coetáneos, cada uno adecuado técnicamente al objetivo pretendido

\footnotetext{
${ }^{8}$ Sánchez Zufiaurre, en 2009: tablas 1, 2 y 4, variables 1 (no 2 ex novo) y 8, coloca Quintanilla, por equivocación, en su "grupo I no alavés", aunque sus variables son la sillería reutilizada y la bóveda baída que equivalen al "grupo 1 alavés" de Id. 2007. Probablemente ocurre lo mismo con Ventas Blancas.
} 

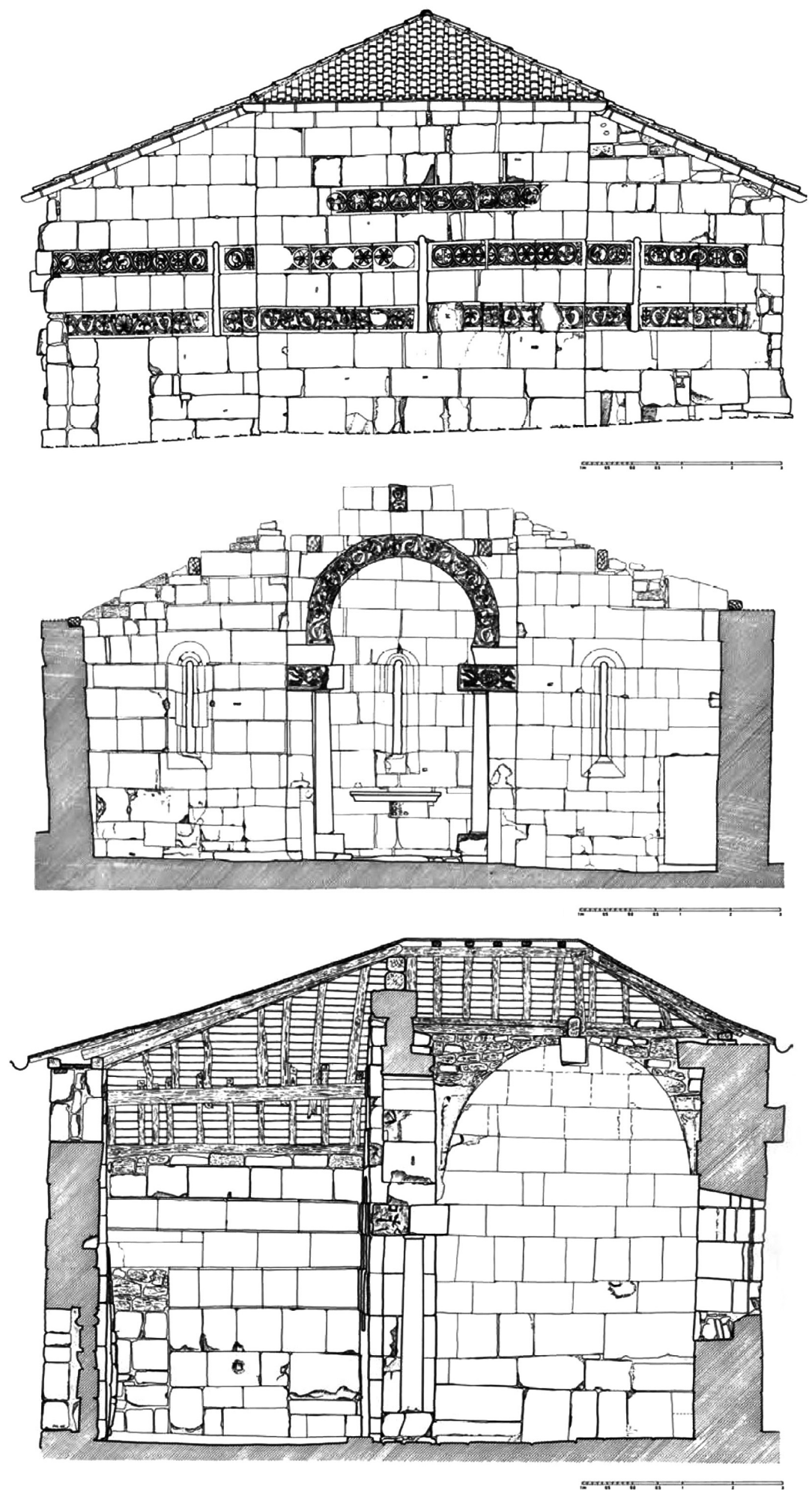

Fig. 14.- Quintanilla de Las Viñas (Burgos). Alzado este y secciones transversal a este y longitudinal a norte. Arbeiter 1990. Escala $1 / 120$. 
en cada caso, como defiende Hoppe. Por ello considero más adecuado denominarlos por su situación o función en el edificio (La Nave: Gómez-Moreno 1966: 129-130; Corzo 1986; Quintanilla: Gómez-Moreno 1966: 131-133; Arbeiter 1990: 397-398; Caballero 1990: 328; Id. y Arce 2004: 166-169; Hoppe 2004: 341-342, 348, 379-380).

El maestro del friso inferior de La Nave individualiza los sillares decorados enmarcándolos con un estrecho filete, característica que Hoppe denomina "fragmentada". De este modo, los temas, aunque aparentan formar un friso corrido, quedan separados de uno a otro sillar. Solo la decoración de los sillares de las ventanas norte y sur del ábside enlazan su decoración sin diferenciarse por sillares [8-9, 14-16]. Pero también en algunos sillares de las ventanas, los temas que los integran se diferencian en cuadros interiores por medio de listeles [3, 8, 15]. En cambio, el maestro del friso superior talla sus roleos de modo continuo entre los sillares del friso ([numeración] de los sillares, según Hoppe 2004: figs. 1-4).

Veamos qué nos puede sugerir sobre el modo de trabajo la reutilización de material propio que se documenta en el friso inferior de La Nave. Dos de las piezas [13, 62], actualmente en la imposta del ábside, estaban preparadas para servir como cimacios de arco: miden la misma longitud, presentan la misma decoración de serpientes y frutos en su frente y decoran sus caras laterales como los actuales cimacios del arco del santuario (Fig. 13). Un error formal, que impedía colocarlas en el lugar al que iban destinadas en origen, pudo desencadenar el proceso de cambio con otras piezas, empezando con las [20 y 27] que las sustituyeron en su lugar previsto. La pieza [62] está incompleta al haberse cortado en origen por su lado derecho para ajustar a su nueva ubicación; y posteriormente, también por el lado izquierdo. La [13] es 3,5 cm más corta que el grueso del muro. La similitud de los frentes de estas parejas de cimacios demuestra que la producción sustituida y la sustituta son una misma y coetánea, incluyendo en ella el tema de los círculos secantes con cuadrifolios [132] que decoró los lados de la pieza sustituida [13]. Por lo tanto este tema no permite suponer una primera fase en la obra como propone Corzo. La reutilización de un capitel sencillo y otro geminado [124/125-126] puede ayudar a explicar este cambio. Su decoración de "hexafolios" formaría parte de un mismo repertorio decorativo con los cuadrifolios del cimacio sustituido. El tamaño de los capiteles actuales y del geminado son similares (Caballero y Arce 2004: 153-155, 170-173; capiteles, Id.: figs. 34 A y 42 A).

Pero el cambio incluyó otras piezas. Se desecharon las piezas [123 a 131] (entre ellas, dos decoradas con cuadrifolios y "ojos de gato" como los laterales de las impostas desechadas y los dos capiteles citados) y se trastocó todo el esquema decorativo como dan a entender, al menos, las piezas cortadas $[14,66]$, una semi-oculta [6] y las que se pueden considerar "recolocadas" por presentar motivos de remate [38, 48]. Se debería reconsiderar hasta qué punto esta "fragmentación" afecta o no al discurso expositivo o si son las permutas ocurridas y que analizamos las que acentúan la sensación fragmentada.

De haber ocurrido como decimos, el material reutilizado no es un residuo de otra obra conservado en un taller estable localizado en un lugar alejado de la obra. Al contrario, procede del error de un taller ocasional (no estable), producido en la propia obra de La Nave, y resuelto sobre la marcha con el menor esfuerzo y gasto posible, desechando la mínima parte, reutilizando el resto y reponiendo la parte imprescindible.

En La Nave y en Quintanilla, los escultores no trabajan en un taller alejado, sino a pie de obra; bien sea decorando los sillares antes de colocarlos o una vez colocados. Antes de colocarlos: en el friso inferior de La Nave, los canteros entregan los sillares y los tallistas los decoran y los devuelven para su colocación definitiva. Una vez colocados: como ocurrió con seguridad en el friso superior de La Nave y en los frisos exteriores de Quintanilla, los escultores tallan los sillares de las hiladas destinadas a formar un friso, aprovechando los andamios antes de desmontarlos. Observemos la diferencia. Hasta ahora hemos visto que los sillares se decoran antes de colocarlos, bien sea en un taller independiente o a pie de obra. La primera vez que se constata con seguridad que se decoran una vez colocados es en la imposta superior de La Nave y en los frisos de Quintanilla. Los canteros construyen de modo que dejan molduras o hiladas lisas preparadas a propósito para tallarlas in situ una vez construido el edificio, lo que en algún caso no se terminó. Esta característica basta para considerar a estos dos edificios, por sí mismos, un modo diferenciado. De una u otra manera, la obra de escultura se prepara a la vez que la obra constructiva: los sillares lisos y los decorados o por decorar se ajustan todos del mismo modo. La decoración no depende de un taller externo o ajeno que la trabaja en su local y la manda una vez ejecutada a la obra, como veíamos en El Trampal (Quintanilla: Arbeiter 1990: abb. 6 y 8. En sus frisos exteriores se conservan marcas, letras y cruces, que pertenecerían al tracista: Caballero 1989: 117-118; La Nave, [54-55 y 58], Caballero y Arce 2004: 155; Hoppe 2004: figs. 22 abajo y 23 arriba).

La coordinación del trabajo debió ser más estrecha cuando los escultores trabajan a pie de obra (friso 
inferior de La Nave), donde el proceso de trabajo tuvo que ser más complejo, favoreciendo, quizás, una equivocación en la ordenación de las piezas; y al contrario, la dirección de obra sería más rigurosa cuando trabajan con los sillares ya colocados, donde sería necesario un equipo combinado.

En ambas iglesias, la estrecha actuación de canteros y escultores y la presencia de distintas maneras de hacer constructiva y decorativa constata que parejas de escultores, que trabajan de forma individual con sus propios patrones formales, aceptaron asumir una colaboración temporal no sólo entre sí sino con la obra de sillería. Dado que la producción decorativa es propia de cada edificio, sus repertorios decorativos se desconocen fuera de sus edificios, al contrario de lo que ocurre en El Trampal donde las producciones proceden de un centro urbano y se distribuyen por su territorio. La existencia de otros edificios repartidos por Burgos, La Rioja y el País Vasco, pertenecientes al mismo horizonte constructivo pero sólo algunos decorados (escultura en Quintanilla, capiteles figurados en La Asunción, estuco en Santa Coloma y mosaico en Tricio), indica que la presencia de talleres decorativos es esporádica y particular y que la colaboración entre canteros y escultores fue temporal para edificios como estos cuyo patrocinio era más importante y a los que se podían destinar más recursos. De nuevo se confirma que, en vez de talleres ajenos y estables, se trata de talleres propios, creados para cada obra concreta, ocasionales, quizás formados por mano de obra ambulante (Caballero y Utrero 2012).

En La Nave, la decoración, que solo existe en el interior, adopta una función polivalente, desarrollando la tendencia observada en El Trampal. El friso inferior actúa como imposta de la bóveda del ábside, cubriendo el testero como friso. Continúa adoptando la función de cimacio de los capiteles del arco de triunfo y termina con la de friso en las naves de "anteábside" y en los muros orientales de las naves del "transepto", donde se interrumpe dada la imposibilidad de continuar por la presencia de los arcos de los porches y los de los de los cierres de las naves laterales del aula. Como señala Garen, de la imposta-friso del ábside "cuelgan" los marcos de las ventanas asemejando alfices decorados, en vez de colocarse de modo que coincidiera con ella la línea de imposta de sus arquillos. La imposta superior de las naves de "anteábside" y de "transepto" actúa de acuerdo con la lógica constructiva pues se presenta en los muros de carga de la bóveda, dejando sin decorar los testeros. A una altura intermedia con las dichas se colocan los cimacios de las columnas de los arcos torales del crucero que actúan también como impostas de los arcos laterales donde no existen columnas, doblando lateralmente, de acuerdo con la norma de vanos y ventanas vista en otros edificios. También los arcos de las puertas exteriores de los porches (abiertos, sin hojas de cierre) tienen impostas que doblan al exterior e interior. Solo las impostas de los arquillos del muro que separa el "transepto" del aula no doblan en sus caras exteriores. Desconocemos si las bóvedas de las naves del aula tuvieron impostas al haberse perdido. Es posible que las laterales no las tuvieran, igual que las de las habitaciones delanteras, y que la central las tuviera, como las del "transepto" y el "anteábside". Tampoco existen indicios de friso (o cornisa) en los porches, que no estuvieron abovedados. Esta distinta manera de actuar, en ruptura con la función arquitectónica o acomodándose a ella, significa la distinta formación (no tradición) y procedencia de ambos escultores (marcos de ventanas, Garen 1992: 300).

Quintanilla se diferencia de los edificios ya vistos, incluyendo La Nave, en que las bandas decorativas se presentan como frisos, exteriores y sin referencia estructural (salvo en la arquivolta del arco de triunfo). Los tres frisos exteriores aprovechan las hiladas constructivas, alternando una decorada y otra lisa. El friso inferior coincide con la línea de umbral de los tragaluces y con el dintel de la puerta de entrada a la nave sur del "transepto"; el intermedio, con la línea de imposta de las ventanas, pero sin más relación con ellas (como vimos en Baños); y el tercero, el más alto, sin referencia estructural.

Los ortoedros que actúan de cimacio-capiteles del arco de triunfo y los sueltos, posiblemente del arco de entrada al crucero desde la nave central del aula, mantienen la forma de cimacio aunque pierden la secuencia de friso y adoptan un tema independiente, decorando solo su frente principal. Recuerdan lejanamente la función de capiteles a los que sustituyen, evidencian su ausencia entre el escaso material reutilizado a disposición de la obra y la ignorancia o la incapacidad de imitarlos. Se relacionan por su forma y función con las piezas del arco de la tribuna y las de los tramos de ante-escalera de San Miguel de Lillo (Oviedo, ¿Ramiro I?, 842-850 d.C.), cuyas producciones se deberían contrastar (Cruz Villalón 2004: 116, "antecedente", con soluciones similares en la arquitectura tunecina aglabí; Caballero et alii 2008: 16-21; Caballero 2012).

En su interior no existen frisos decorados. Las hiladas que corresponden en altura con los frisos exteriores y una cuarta más, por encima, se diferencian por estar resaltadas, al modo de una almohadilla continua. No se puede aventurar qué función tendrían estas hiladas al margen de la obvia de destacar por su ligero resalte. 
No se puede asegurar que estuvieran preparadas para la decoración pues la conservada es en bajo relieve. Además estas hiladas almohadilladas no se presentan uniformes; en la nave norte del "transepto" faltan en su muro occidental; en el ábside solo aparece la tercera, a la altura del arranque de las pechinas; y en la nave de "transepto" sur, la cuarta en el muro oriental (Arbeiter 1990: 406-407, considera posible la hipótesis de Kingsley, que las supone preparadas para decorar).

En la iglesia y en su entorno hay más piezas sueltas que se supone que pertenecen a su parte desaparecida. Se conocen más de quince, entre ellos dos supuestos cimacio-capiteles, figurados, que se situarían en el arco de paso del crucero a la nave central ${ }^{9}$. Un grupo, conservado en el Museo de Burgos, similar a los frisos exteriores, posee un escaso grosor como si correspondiera a un distinto aparejo de chapado (Camps 1963: figs. 413 y 420; Andrés y Abásolo 1982: láms. 22 y 23; Arbeiter 1990: 399).

Es de señalar que ni en La Nave ni en Quintanilla se conservan indicios de canceles, al contrario de lo que ocurre en las iglesias anteriores. No se han descubierto restos de placas o largueros decorados y tampoco hay huellas en las paredes que correspondieran a su sujeción. Los sistemas litúrgicos se han sustituido en La Nave por un muro de cierre con ventanas y en Quintanilla por un muro cerrado con puertas, que cortan o dificultan el acceso y la visión desde las naves y las habitaciones laterales del aula al "transepto". Una solución estructural parecida ya se había adoptado en El Trampal donde, sin embargo, se mantenían los canceles. Se puede suponer este un indicio diferencial y un alejamiento de la tradición hispana tardoantigua de estas iglesias con respecto a las que aún presentan decoración litúrgica. Ello no obsta para que mantuvieran altares de forma tradicional, con decoración similar a la arquitectónica y de fecha post-visigoda (Sastre de Diego 2009).

\section{CONCLUSIONES}

El análisis arqueológico de este grupo homogéneo de edificios de la alta Edad Media diferencia distintos modos de producción constructiva y decorativa. Estos modos permiten proponer un orden secuencial, de carácter tipológico, con cierto valor cronológico. Pero de él no se deben deducir unas relaciones lineales entre los modos diferenciados; hay que aceptar la existencia de relaciones intermedias, desconocidas para nosotros, que dificultan comprender la verdadera

\footnotetext{
${ }^{9}$ Uno de los cimacios fue robado en agosto de 2005 .
}

situación temporal y relacional entre sí de los talleres productivos a que pertenecen estos modos, por más que las conclusiones obtenidas faciliten plantear el establecimiento de esas relaciones y su cronología. Esta situación solo se puede superar si se continúa el análisis sistemático del territorio construido altomedieval, siguiendo el ejemplo efectuado en Álava por Sánchez Zufiaurre (2007). Mientras, se puede completar nuestro análisis con otros edificios del mismo o de distintos grupos.

Con respecto a la toma de decisión sobre la utilización de material, nuevo, procedente de cantera, o reutilizado, de expolio, tuvieron que influir, entre otras razones, la capacidad técnica del taller; el conocimiento del yacimiento o la cantera; el grado de facilidad, extracción, acceso y traslado; el tipo, calidad y adecuación del material a la finalidad que se pretendía; las existencias que estuvieran a disposición; e incluso la capacidad de almacenamiento del taller que reutiliza. El esfuerzo técnico diferencial entre la manera nueva o la manera reutilizada no fue la única determinante para que se generalizase una de ellas. De hecho ambas variantes, coetáneas tanto en construcción como en decoración, se alternaron y ocurrieron, como hemos visto, según fines y con variantes diferentes, y según casos, zonas y posiblemente fechas diferentes. (Utrero y Sastre de Diego 2012).

Aunque se trate de una aparente excepción, la producción constructiva de El Trampal supone la alternancia de mampostería (albañil) y sillería (cantero) en un edificio abovedado y decorado. Además, los entornos de estos edificios pudieron completar sus conjuntos con edificios de mampostería reforzada, como ocurre en Melque con los edificios monásticos. Un sistema de edificios, como el llamado asturiano, sincrónico al grupo estudiado, ofrece mayoritariamente aparejo de mampostería reforzada, indicando que, para lograr una referencia adecuada, hay que ampliar el ángulo de visión. Estos argumentos obligan a no identificar sillería con abovedamiento ni con decoración. Emparejarlos conduce a una conclusión falsa. Por parecida razón también es falso concluir que mampostería y sillería derivan o sencillamente se suceden. Está demostrado que ambas técnicas son coetáneas. De hecho ambas se necesitan entre sí.

Una de las características generalizadas en el grupo estudiado es la utilización de la regla y el desconocimiento de la escuadra en el corte de la sillería (ausencia de sillería escuadrada), ya sea nueva o reutilizada. El uso de la regla se produjo entre los siglos VIII al X. El estudio de sus maneras de uso y sus procesos confirmará si se trata de una incorporación novedosa, como pienso, o una perduración tradicional. Su fecha final y la sustitución 
por el nuevo instrumento de la escuadra se debe situar entre la de construcción de los cuerpos de las iglesias de San Salvador de Valdediós (Asturias) y San Miguel de Escalada (León. Sillería sin escuadrar) y la de sus pórticos (sillería escuadrada), o entre las dos primeras etapas de San Román de Tobillas (Álava, Tobillas/2, año 939); esto es, dentro del siglo X (Azkarate 1995; Caballero y Utrero 2005: 181 y fig. 4; Sánchez Zufiaurre 2007: 272-273 y 297-298; Caballero y Utrero 2012).

La arquitectura hispánica abovedada de época altomedieval se caracteriza por el uso sistemático de frisos con función arquitectónica y constructiva. Los frisos presentan esta doble función en impostas de bóvedas; cornisas, rematando los paramentos; arquivoltas, decorando los frentes de los arcos; y en un estadio más avanzado, en frisos independizados de una función constructiva. Se diferencian de las basílicas hispánicas tardoantiguas, donde solo se utilizan como cimacios de columnas. Como una variante característica, las impostas soportan las bovedillas en las jambas o alféizares de los vanos arcuados (ventanas, arcos de paso o ábsides), rematando el friso por los paramentos exterior e interior del muro. La relación entre arquitectura abovedada (no necesariamente de sillería) y frisos decorados conforma un modelo acabado ya en sus primeras manifestaciones que es imposible explicar por una evolución interna sino que necesita la llegada de expertos y modelos foráneos, con prototipos plenamente formados. Estos modelos constructivo/decorativos necesitan talleres y patronos importados que se requieren mutuamente, inutilizando la búsqueda de precedentes locales (Utrero e.p.).

Estos edificios (desde los monasterios pioneros de El Trampal y Melque) ajustaron equipos de construcción y decoración complejos, autónomos y peculiares, introduciendo las novedades del abovedamiento, con una organización espacial acomodada a resistirlo, y de la decoración arquitectónica adecuada. La multiplicidad de talleres (cantería, albañilería, carpintería, herrería, escultura, marmolería y estuco), con su organización diferenciada y especializada, supone una ruptura con los ambientes técnicos tardoantiguos (salvo en la citada escultura mobiliaria) y una excepción en el ambiente peninsular de su momento, lo que se puede explicar por la llegada de modelos y talleres extranjeros y desarrollados.

La comparación entre los ejemplos analizados y los conocidos de época tardoantigua obliga a aceptar que la utilización del mobiliario litúrgico de los canceles en la producción arquitectónica continúa una tradición formal y técnica que pervive durante la alta Edad Media, a pesar de la nueva organización espacial, con barreras arquitectónicas, que invalidaba su uso.
El Trampal presenta ambos sistemas como indicio de una situación de transición.

Se diferencian dos maneras básicas de producción, estable y ocasional, referidas ya a talleres como a ciclos productivos y tanto a la construcción como a la decoración. El taller decorativo emeritense que sirve a El Trampal impostas y canceles ofrece los caracteres más claros de la manera estable: taller fijo; con práctica de trabajo tradicional (excepto en el repertorio decorativo); de producción dispersa por el territorio; y prefabricada, de modo que producción decorativa y puesta en obra son independientes. La obra constructiva del grupo riojano-alavés, de sillería reutilizada y bóvedas baídas de toba es un ejemplo de talleres (ciclo productivo) estables, aunque para la construcción este concepto se refiera a cierta homogeneidad de sus caracteres y de su distribución territorial. Los talleres ocasionales se caracterizan por no tener referencias similares fuera de cada caso concreto. Entre ambas categorías extremas hay que distinguir variantes intermedias.

Los talleres constructivos y los decorativos son básicamente independientes entre sí; cada uno realiza labores definidas y diferentes. Pero necesitan establecer unas normas de relación entre ellos que oscilan entre la asociación, estrecha pero temporal; la colaboración, manteniendo la independencia; y la coordinación, de consistencia y duración variable. Estas diferencias permiten plantear modos diferentes de relación entre construcción y decoración. En un resumen necesitado de matizaciones serían el de asociación en Melque, entre canteros y estucadores; de colaboración entre constructores y marmolistas en El Trampal, Melque y Baños; de coordinación y colaboración entre constructores y escultores en La Nave y Quintanilla.

Una visión simple puede concluir que los medios (entendidos en sentido amplio: instrumentos, formación, circunstancias culturales, económicas y sociales) empleados por estas producciones son básicos y escasos. Los actores no son expertos; los conocimientos técnicos son insuficientes; no existen cadenas de formación consolidadas; y el entorno social de financiadores, centros y productores se encuentra en una transformación profunda. Todo ello restaría a los artesanos capacidad para ser propietarios de medios, administrar recursos y poseer un estatus que les hiciera visibles a través de las obras que por ello aparecen dispersas y aisladas. Esta percepción es aparente. Las obras demuestran los conocimientos previos, las evidentes capacidades y el provecho que obtienen los productores de los medios a su alcance, sin restricciones, y los más avanzados de su momento. Constructores y decoradores son conscientes de que se deben relacionar acomodándose a las condiciones del patronazgo, a las posibilidades de la obra 
y a sus conocimientos técnicos y formales. Aunque predominan las obras aisladas, se distinguen grupos de arquitectura y escultura con caracteres técnicos y formales similares. No debe engañar la aparente situación de escasez, dado que los resultados obtenidos por estos talleres, técnica, formal, utilitaria y estéticamente, son ingeniosos, de alta calidad y denotan la inteligencia de sus actores. Los talleres se ajustan a una economía de producción; es el acto de producir lo que administran y acomodan a los medios que tienen a su disposición, a las necesidades que les vienen impuestas y a las dificultades que no pueden superar. El juicio de Utrero cuando considera "la combinación de piezas reutilizadas y nuevas" resultado "de una economía de esfuerzos" (o de producción, como aquí la denomino) y no "de un contexto económico y productivo precario", es extrapolable a todo el proceso de producción constructivo y decorativo (Utrero e.p.: n. 14).

\section{BIBLIOGRAFÍA}

Alba, M. 2007: "Diacronía de la vivienda señorial de Emerita (Lusitania, Hispania): desde las domus alto imperiales y tardoantiguas a las residencias palaciales omeyas (siglos I-IX)", G. P. Brogiolo y A. Chavarría (eds.), Archeologia e Società tra Tardo Antico e Alto Medioevo (Padova, 2005), Mantova, 163-192.

Andrés Ordax, S. y Abásolo Álvarez, J. A. 1982: La ermita de Santa María. Quintanilla de las Viñas (Burgos), Burgos.

Arbeiter, A. 1990: "Die westgotenzeitliche Kirche von Quintanilla de las Viñas. Kommentar zur architektonischen Gestalt", Madrider Mitteilungen 31, 393-427.

Arbeiter, A. 2001: "II. Disposición y construcción del Templo", R. Barroso y J. Morín de Pablos, La iglesia de Santa María de Quintanilla de las Viñas, Madrid, 45-78.

Azkarate Garai-Olaun, A. 1995: Aportaciones al debate sobre la arquitectura prerrománica peninsular: la iglesia de San Román de Tobillas (Álava), Archivo Español de Arqueología 68, 189-214.

Balmaseda Muncharaz, L. J. 1998: Arte ornamental arquitectónico visigodo en la provincia de Toledo, (tesis doctoral), dos volúmenes, Madrid (manuscrito).

Balmaseda Muncharaz, L. J. 2007: "Algunos problemas de la escultura visigoda toledana”, L. Caballero y P. Mateos (eds.), Escultura decorativa tardorromana y altomedieval en la Península Ibérica, Anejos de Archivo Español de Arqueología XLI, Madrid, 275-300.
Bango Torviso, I. G. 2001: Arte prerrománico hispano. El arte en la España cristiana de los siglos VI al $X I$, vol. VIII-II, Madrid.

Barroso Cabrera, R. y Morín de Pablos, J. 2007: Regia Sedes Toletana, vol. II, Toledo.

Bianchi, G., 1996: "Trasmissione dei saperi tecnici e analisi dei procedimenti costruttivi", Archeologia dell'Architetture 1, 53-64.

Caballero Zoreda, L. y Latorre Macarrón, J. I. 1980: La iglesia y el monasterio visigodo de Santa María de Melque (Toledo). Arqueología y arquitectura. San Pedro de la Mata (Toledo) y Santa Comba de Bande (Orense), Excavaciones Arqueológicas en España 109, Madrid.

Caballero Zoreda, L. 1989: "Pervivencia de elementos visigodos en la transición al mundo medieval. Planteamiento del tema", III Congreso de Arqueología Medieval Española, Oviedo, I, 111-134.

Caballero Zoreda, L. 1990: "Una conjetura sobre la iglesia visigoda de San Pedro de La Nave (prov. Zamora)", I Congreso de Historia de Zamora, Actas, Zamora, 2, 317-355.

Caballero Zoreda, L. 1994/95: "Un canal de transmisión de lo clásico en la alta Edad Media española. Arquitectura y escultura de influjo omeya en la Península Ibérica entre mediados del siglo VIII e inicios del siglo X", al Qantara 15/2 y 16/1, 321-348 y 107- 124.

Caballero Zoreda, L. y Feijoo Martínez, S. 1998: "La iglesia altomedieval de San Juan Bautista en Baños de Cerrato (Palencia)", Archivo Español de Arqueología 71, 181-242.

Caballero Zoreda, L. y Fernández Mier, M. 1999: "Notas sobre el complejo productivo de Melque (Toledo). Prospección del territorio y análisis de carbono-14, polínicos, carpológicos y antracológicos y de morteros", Archivo Español de Arqueología 72, 199- 239.

Caballero Zoreda, L. y Sáez Lara, F. 1999: La Iglesia Mozárabe de Santa Lucía de El Trampal, Alcuéscar (Cáceres). Arqueología y Arquitectura, Memorias de Arqueología Extremeña 2, Junta de Extremadura.

Caballero Zoreda, L. y Velázquez Soriano, I. 1999: "Un grafito latino en el cimborrio central de la iglesia”, L. Caballero, y F. Sáez, La iglesia Mozárabe de Santa Lucía del Trampal, 203-209.

Caballero Zoreda, L. 2001: “Aportación a la arquitectura medieval española. Definición de un grupo de iglesias castellanas, riojanas y vascas", Actas del $V$ Congreso de Arqueología Medieval Española, Valladolid, 1, 221-233.

Caballero Zoreda, L. 2004: "La excavación arqueológica del solar primitivo de la iglesia de San Pedro 
de La Nave (1997)", L. Caballero (coord.), La iglesia de San Pedro de La Nave, Zamora, 79-113.

Caballero Zoreda, L. y Arce, F. 2004: "Arqueología de la arquitectura de la iglesia de La Nave", L. Caballero (coord.), La iglesia de San Pedro de La Nave, Zamora, 115-197.

Caballero Zoreda, L. y Utrero Agudo, Mª Á. 2005: "Una aproximación a las técnicas constructivas de la Alta Edad Media en la Península Ibérica. Entre visigodos y omeyas", Arqueología de la Arquitectura 4, 169-192.

Caballero Zoreda, L. 2007: "El monasterio de Balatalmelc, Melque (San Martín de Montalbán, Toledo). En el centenario de su descubrimiento”, J. López Quiroga, M. Martínez Tejera y J. Morín de Pablos (eds.), III Encuentro Internacional: Monasteria et Territoria, British Archaeological Reports, Internacional Series S1720, Oxford, 91-120.

Caballero Zoreda, L. y Arce Sainz, F., 2007: "Producción decorativa y estratigrafía”, L. Caballero y P. Mateos (eds.), Escultura decorativa tardorromana y alto medieval en la Península Ibérica, Anejos de Archivo Español de Arqueología 41, Madrid, 233-274.

Caballero Zoreda, L., Utrero Agudo, Ma . A., Arce Sainz, F. y Murillo Fragero, J. I. 2008: "La iglesia de San Miguel de Lillo (Asturias). Lectura de paramentos 2006", Territorio, sociedad y poder 2, Oviedo.

Caballero Zoreda, L. 2012: “Observaciones arqueológicas sobre producción arquitectónica y decorativa de las iglesias de S. Miguel de Lillo y Santianes de Pravia”, L. Caballero, P. Mateos y C. García de Castro (eds.), Asturias entre visigodos y mozárabes (2010), Anejos de Archivo Español de Arqueología, Madrid, 89-124.

Caballero Zoreda, L. 2012: “A propósito del centenario del 711. Apuntes sobre método de la Arqueología de la Arquitectura", V Jornadas Complutenses de Arte Medieval, (Madrid 2011), Anales de Historia del Arte, 101-130.

Caballero Zoreda, L. y Moreno Martín, F. J., 2013: "Balatalmelc, Santa María de Melque. Un monasterio del siglo VIII en territorio toledano", Teoría y práctica fiscal en el Occidente islámico y en Dar al-islam (siglos VII-IX) (Barcelona 2010) British Archeological Reports, Internacional Series 2525, Oxford, 182-184.

Caballero Zoreda, L. y Moreno Martín, F. J. e.p.: "Sobre la dimensión epistemológica e histórica de una propuesta historiográfica. El modelo explicativo mozarabista", Cruce de Culturas. Arquitectura y su ornamentación y decoración en la Península Ibérica (siglos VI-X/XI), Heidelberg.
Caballero Zoreda, L y Utrero Agudo, Ma . Á. 2012: "Cómo funcionaban los talleres constructivos en la Alta Edad Media Hispánica", Homenaje al profesor José Ángel García de Cortazar, Santander. T. I, 427-440.

Camps Cazorla, E. 1963: "El arte hispanovisigodo", España Visigoda (414-711 de J.C.), vol. III, Madrid.

Corzo Sánchez, R. 1986: San Pedro de la Nave. Estudio histórico y arqueológico de la iglesia visigoda, Zamora.

Cruz Villalón, M. 1985: Mérida visigoda. La escultura arquitectónica y litúrgica, Badajoz.

Cruz Villalón, M. 2004: "Quintanilla de las Viñas en el contexto del arte altomedieval. Una revisión de su escultura", Antigüedad y Cristianismo 21, 101-135.

Gans, U. 1992: Korinthisierende Kapitelle der römischen Kaiserzeit, Köln.

Garen, S. 1992: "Santa María de Melque and Church Construction under Muslim Rule", Journal of the Society of Architectural Historians 51, 288-305.

Gómez-Moreno, M. 1919: Iglesias Mozárabes. Arte español de los siglos IX a XI, Madrid.

Gómez-Moreno, M. 1927: Catálogo Monumental de España. Provincia de Zamora. 1903-1905, Madrid.

Gómez-Moreno, M. 1966, "Primicias del arte cristiano español”, Archivo Español de Arte 39, 101-139.

Hamilton, R. W. 1959: Khirbat al Mafjar: An Arabian Mansion in the Jordan Valley, Oxford.

Hoppe, J. M. 2004: "Ensayo sobre la escultura de San Pedro de La Nave" 1, L. Caballero (coord.), La iglesia de San Pedro de La Nave, Zamora, 323-425.

Hoyo, J. del. 2006: “A propósito de la inscripción dedicatoria de San Juan de Baños”, C. Fernández Martínez y J. Gómez Pallarés (eds.), Temptanda Viast. Nuevos estudios sobre la poesía epigráfica latina, SPUAB, CDROM 18.

Jorge Aragoneses, M. 1957: "El primer Credo epigráfico visigodo y otros restos coetáneos, descubiertos en Toledo", Archivo Español de Arte 30, 295-323.

Juan Ares, J. de. 2000: "La alcazaba de Vascos: Aproximación a su evolución y características", Entre el Califato y la Taifa: Mil años del Cristo de la Luz (1999), Toledo, 307-315.

Larrea, J. J y Pastor, E. 2012: Alaba wa-l Qila: la frontera oriental en las fuentes escritas de los siglos VIII y IX, Asturias entre visigodos y árabes, Anejos de Archivo Español de Arqueología 63, 307-330.

Martínez Lillo, S. 1998: Arquitectura militar andalusí en la Marca Media. El caso de Talab ra, Talavera de la Reina.

Mateos Cruz, P. 1999: La basílica de Santa Eulalia de Mérida. Arqueología y urbanismo, Anejos de Archivo Español de Arqueología 19, Madrid. 
Moreno Martín, F. J. 2003/2004: El yacimiento de Los Hitos en Arisgotas (Orgaz, Toledo). Aproximación a la arquitectura monástica altomedieval (trabajo de investigación), Madrid (manuscrito).

Palol Salellas, P. de. 1963: Excavaciones en la necrópolis de San Juan de Baños (Palencia), Excavaciones Arqueológicas en España 32, Madrid.

Palol Salellas, P. de. 1988: La basílica de San Juan de Baños, Palencia.

Palol Salellas, P. de. 1991: “Arte y arqueología”, España visigoda, vol. III/2, 269-428, Madrid.

Pavón Maldonado, B. 1990: El arte hispanomusulmán en su decoración floral, Madrid.

Regueras Grande, F. y García-Aráez Ferrer, H. 2001, Scriptorium. Tábara visigoda y mozárabe, Tábara.

Rojas Rodríguez-Malo, J. M. y Gómez Laguna, A. J. 2009: "Intervención arqueológica en la Vega Baja de Toledo. Características del centro político y religioso del reino visigodo", L. Caballero, P. Mateos y M $\mathrm{M}^{\mathrm{a}}$. A. Utrero (eds.), El siglo VII frente al siglo VII: arquitectura, Anejos de Archivo Español de Arqueología 51, 45-90, Madrid.

S.a. 2010: Arqueología aplicada al estudio e interpretación de edificios históricos. Últimas tendencias metodológicas, Madrid. http://www.calameo. com/read/000075335b34985f34eff

Sánchez Velasco, J. 2006: Elementos arquitectónicos de época visigoda en el Museo Arqueológico de Córdoba, Junta de Andalucía.

Sánchez Zufiaurre, L. 2007: Técnicas constructivas medievales. Nuevos documentos arqueológicos para el estudio de la alta Edad Media en Álava, Vitoria-Gasteiz.

Sánchez Zufiaurre, L. 2009: "Metodología. Las iglesias de Álava de los siglos IX-XI y las consideradas iglesias del siglo VII", L. Caballero, P. Mateos y M. A. Utrero (eds.), El siglo VII frente al siglo VII: Arquitectura, Anejos de Archivo Español de Arqueología LI, 231-240.
Sastre de Diego, I. 2009: Los altares de las iglesias hispanas. Siglos V-X. Estudio arqueológico (tesis doctoral), Madrid (manuscrito).

Schlunk, H. 1947: Arte visigodo, Ars Hispaniae II, Madrid.

Schlunk, H. 1965: "Die Auseinandersetzung der Christlichen un der Islamischen Kunst auf dem Gebiete der Iberischen Halbinsel bis zum Jahre 1000", L'Occidente e l'Islam nell'Alto Medioevo, Settimane di Studio del Centro Italiano di Studi sull'Alto Medioevo II, Spoleto, 903-931.

Schlunk, H. 1970: "Beiträge zur kunstgeschichtlichen Stellung Toledos im 7. Jahrhundert", Madrider Mitteilungen 11, 161-186.

Schlunk, H. y Hauschild, Th. 1978: Die Denkmäler der frühchristlichen und westgotischen Zeit, Hispania Antiqua, Mainz \& Rhein.

Utrero Agudo, Ma . Á. 2006: Iglesias tardoantiguas y altomedievales en la Península Ibérica. Análisis arqueológico y sistemas de abovedamiento, Anejos de Archivo Español de Arqueología XL, Madrid.

Utrero Agudo, Ma . Á. 2010: "Late-Antique and Early Medieval Hispanic Churches and the Archaeology and Reinterpretation of Constructions Chronologies and Contextus", Medieval Archeology 54, 1-33.

Utrero Agudo, $M^{\mathrm{a}}$. Á. e.p.: "Producción arquitectónica y decorativa cristiana en la Península Ibérica, siglos VI-X. Cambio tecnológico y canales de transmisión". Cruce de Culturas. Arquitectura y su ornamentación y decoración en la Península Ibérica (siglos VI-X/XI) (2009), Heidelberg.

Utrero Agudo, Ma . y Sastre de Diego, I. 2012: "Reutilizando materiales en las construcciones de los siglos VII-X, ¿una posibilidad o una necesidad?", V Jornadas Complutenses de Arte Medieval (Madrid 2011), Anales de Historia del Arte 22, 309-323. 